\title{
HGF-independent regulation of MET and GAB1 by nonreceptor tyrosine kinase FER potentiates metastasis in ovarian cancer
}

\author{
Gaofeng Fan, ${ }^{1}$ Siwei Zhang, ${ }^{1,2}$ Yan Gao, ${ }^{3}$ Peter A. Greer, ${ }^{3}$ and Nicholas K. Tonks ${ }^{1}$ \\ ${ }^{1}$ Cold Spring Harbor Laboratory, Cold Spring Harbor, New York 11724, USA; ${ }^{2}$ Department of Molecular Genetics and \\ Microbiology, Stony Brook University, Stony Brook, New York 11794, USA; ${ }^{3}$ Department of Biomedical and Molecular Sciences, \\ Queen's University, Kingston, Ontario K7L3N6, Canada
}

\begin{abstract}
Ovarian cancer cells disseminate readily within the peritoneal cavity, which promotes metastasis, and are often resistant to chemotherapy. Ovarian cancer patients tend to present with advanced disease, which also limits treatment options; consequently, new therapies are required. The oncoprotein tyrosine kinase MET, which is the receptor for hepatocyte growth factor (HGF), has been implicated in ovarian tumorigenesis and has been the subject of extensive drug development efforts. Here, we report a novel ligand- and autophosphorylation-independent activation of MET through the nonreceptor tyrosine kinase feline sarcoma-related (FER). We demonstrated that the levels of FER were elevated in ovarian cancer cell lines relative to those in immortalized normal surface epithelial cells and that suppression of FER attenuated the motility and invasive properties of these cancer cells. Furthermore, loss of FER impaired the metastasis of ovarian cancer cells in vivo. Mechanistically, we demonstrated that FER phosphorylated a signaling site in MET: Tyr1349. This enhanced activation of RAC1/PAK1 and promoted a kinaseindependent scaffolding function that led to recruitment and phosphorylation of GAB1 and the specific activation of the SHP2-ERK signaling pathway. Overall, this analysis provides new insights into signaling events that underlie metastasis in ovarian cancer cells, consistent with a prometastatic role of FER and highlighting its potential as a novel therapeutic target for metastatic ovarian cancer.
\end{abstract}

[Keywords: ovarian cancer; tyrosine phosphorylation; FER; MET; GAB1]

Supplemental material is available for this article.

Received November 19, 2015; revised version accepted June 7, 2016.

Ovarian cancer is the leading cause of death from gynecological malignancies and ranks fifth of all cancer-related deaths in women (Siegel et al. 2015). Despite recent advances in surgery and chemotherapy, the overall survival from ovarian cancer has not improved significantly for the last four decades. In particular, the failure to detect this "silent killer" disease early results in tumor progression to an advanced stage, accompanied by metastasis. Although dissemination of most cancer cells requires migration within the vasculature, the exfoliated ovarian carcinoma cells may be transported throughout the peritoneal cavity to adjacent organs by normal peritoneal flu$\mathrm{id}$; this lack of an anatomical barrier further accelerates metastasis (Longuespee et al. 2012). It is almost impossible to render patients free of the disease with surgery due to this diffuse feature, and $\sim 70 \%$ of patients present with disease that has spread beyond the ovaries. Therefore, delineating the molecular basis for ovarian carcino-

Corresponding author: tonks@cshl.edu Article is online at http://www.genesdev.org/cgi/doi/10.1101/gad.284166. 116. ma metastasis may not only inform prognosis but also promote the identification of novel therapeutic targets.

The $c$-Met oncogene, which encodes a receptor protein tyrosine kinase (PTK), and its cognate ligand, hepatocyte growth factor (HGF), have been shown to play an important role in the aggressive behavior of ovarian cancer. c-MET is overexpressed in up to $60 \%$ of tumors from patients with ovarian cancer (Huntsman et al. 1999; Koon et al. 2008), and its expression has been implicated in the early steps of ovarian carcinogenesis (Wong et al. 2001) as well as the advanced stages of the disease associated with poor prognosis (Ayhan et al. 2005; Sawada et al. 2007). Targeting c-MET by RNAi in ovarian carcinomaderived cell lines inhibited adhesion, invasion, peritoneal dissemination, and tumor growth through an a $5 \beta 1$ integrin-dependent mechanism (Sawada et al. 2007).

(C) 2016 Fan et al. This article is distributed exclusively by Cold Spring Harbor Laboratory Press for the first six months after the full-issue publication date (see http://genesdev.cshlp.org/site/misc/terms.xhtml). After six months, it is available under a Creative Commons License (Attribution-NonCommercial 4.0 International), as described at http://creativecommons.org/licenses/by-nc/4.0/. 
MET is produced as a single-chain precursor $(\sim 170$ $\mathrm{kDa})$; through cleavage at a furin site that is located between residues 307 and 308, the mature form of MET is formed with a highly glycosylated extracellular a subunit (45 kDa) and a transmembrane $\beta$ subunit (140 kDa) linked by a disulphide bond (Birchmeier et al. 2003). The kinase domain and the C-terminal tail, which are important for signal propagation, are within the $\beta$ subunit. In the classic ligand-dependent activation model, binding of HGF induces MET dimerization and autophosphorylation of tyrosine residues in its activation loop (Tyr1234 and Tyr1235). In this form, the receptor PTK acquires enhanced kinase activity and further autophosphorylates two additional tyrosines in its C terminus; namely, 1349 and 1356. This creates docking sites for adaptor proteins with $\mathrm{SH} 2$ or $\mathrm{PH}$ domains, including GRB2, GAB1, and SHC (Trusolino et al. 2010; Gherardi et al. 2012). Intracellular signaling components are then recruited to the adaptor proteins to activate further the downstream RAS-RAF-MEK-MAPK, PI3K-AKT, and STAT3 signaling pathways (Trusolino et al. 2010). Accordingly, several strategies have been adopted to inhibit c-MET activation in cancers, including monoclonal antibodies against HGF to block ligand-receptor binding or small molecule inhibitors that target the receptor tyrosine kinase (RTK) function directly (Comoglio et al. 2008). However, in ovarian cancer, AMG-102, a humanized antibody developed against HGF, which is capable of preventing HGF binding to c-MET and subsequent downstream activation, showed very weak anti-tumor effect as a monotherapy in clinical trials (Gordon et al. 2010; Liu et al. 2010). Gastric cancer also developed resistance to a potent small molecule inhibitor of MET, PHA-665752, by selectively harboring KRAS amplification (Cepero et al. 2010) and/or triggering downstream BRAF and CRAF activation (Petti et al. 2015). These observations suggest that there may still be unknown mechanisms by which the cancer cell may bypass robust HGF-MET inhibition and reinitiate downstream signaling pathways in a ligand-independent manner.

Instead of gene mutations or the production of autocrine or paracrine HGF, MET overexpression underlies the most frequent cause of HGF/MET hyperactivation in human tumors (Boccaccio and Comoglio 2006). Such high levels of MET expression alone may facilitate receptor oligomerization and tyrosine kinase activation in a ligand-independent manner. Alternatively, it is also conceivable that some yet to be identified PTK(s) may activate MET and/or its downstream signaling cascades in the absence of HGF. Whereas treating with MET inhibitor in the former case could still inhibit activation of the receptor, the latter possibility would be consistent with the failure of HGF-MET inhibition to treat cancer cells. Here, we report an alternative, HGF-independent activation of MET through a nonreceptor PTK, feline sarcomarelated (FER). We demonstrate that FER was essential for ovarian cancer cell motility and invasiveness both in vitro and in vivo and may attenuate the responsiveness of ovarian cancer cells to the MET inhibitor PHA-665752. Considering that frequent amplification/up-regulation of MET accounts for therapy resistance and poor prognosis in a variety of cancers, including ovarian cancer, our findings pinpoint an important new signaling hub involving the role of FER in MET activation, which may provide a novel strategy for therapeutic intervention.

\section{Results}

Up-regulated non-RTK FER was responsible for elevated motility and invasiveness of ovarian cancer-derived cell lines

Aberrant activation of $\beta$-catenin-mediated Wnt signaling pathways has been reported to be a feature of ovarian cancer (Barbolina et al. 2011; Arend et al. 2013). Furthermore, deregulation of PI3K/PTEN and Wnt/ $\beta$-catenin signaling pathways by conditional inactivation of the Pten and $A p c$ tumor suppressor genes in murine ovarian surface epithelium results in the formation of adenocarcinomas morphologically similar to human ovarian endometrioid adenocarcinoma (Wu et al. 2007). In light of this, we compared the distribution of $\beta$-Catenin between two human ovarian surface epithelial (HOSE) cell lines (Tsao et al. 1995) and 11 ovarian carcinoma-derived cell lines. The result suggested an increase of nuclear $\beta$-catenin in most ovarian cancer cells tested (Supplemental Fig. S1A). Concomitantly, phosphorylation of $\beta$-catenin on Tyr142 was also enhanced in tumor cells (Supplemental Fig. S1B). We and others have reported previously that the PTK FER is a key regulator of $\beta$-catenin phosphorylation (Piedra et al. 2003; Xu et al. 2004). Our data now also reveal that expression of FER was up-regulated in all 11 ovarian cancer cell lines (Fig. 1A). In addition, ectopic expression of FER in control HOSE11-12 cells resulted in a dramatic increase in Tyr142 phosphorylation of $\beta$-catenin (Fig. 1B) as well as in cell motility (Fig. 1C). The aim of these studies is to investigate the potential importance of FER in the control of cell migration and invasion and its impact on ovarian cancer metastasis.

It is important to note that, like breast cancer, ovarian cancer is not a single disease; instead, there are various categories of ovarian cancer. In our panel of cells, we tried to sample this diversity. Suppression of FER by RNAi (Fig. 1D) led to a pronounced decrease in the motility of three different ovarian cancer cell lines (Fig. 1E) as well as in cell invasion (Fig. 1F). These phenotypes that were associated with loss of FER were not due to changes in proliferation because we did not detect any change in cell growth by either CellTiter-Glo cell viability assay (Fig. 1G) or Ki67 staining (Fig. $1 \mathrm{H}$ ). On the basis of genomic data analysis (Domcke et al. 2013), CAOV4 and CAOV3 cells are categorized as high-grade serous ovarian carcinoma (HGSOC) lines. To solidify our observations further, we tested the role of FER in another HGSOC line, OVCAR4. Compared with the HOSE11-12 control, FER expression was also upregulated in OVCAR4 cells (Supplemental Fig S2A). Knockdown of FER with shRNA (Supplemental Fig S2B) impaired both cell migration (Supplemental Fig S2C) and invasion (Supplemental Fig S2D), suggesting a critical role of FER in regulating ovarian cancer cell motility and invasiveness, especially in HGSOC lines. 
Fan et al.

A

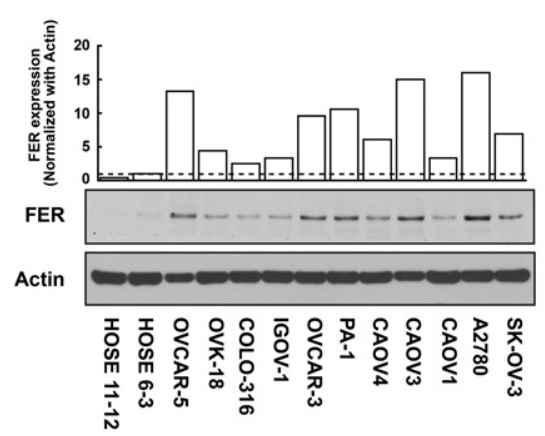

C

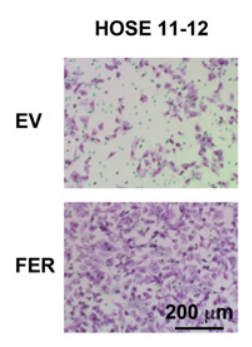

B

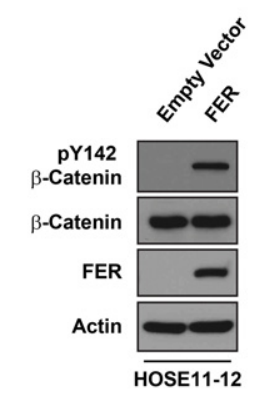

D

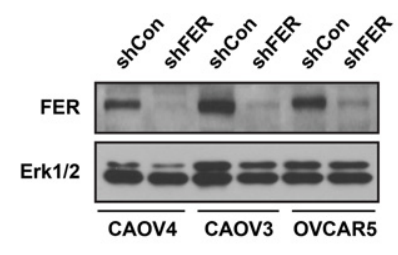

F
E

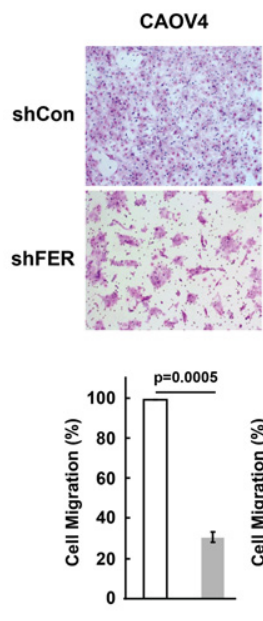

\begin{abstract}
OVCAR5
\end{abstract}

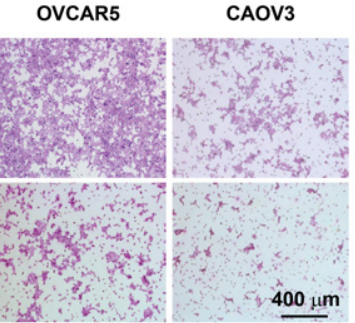

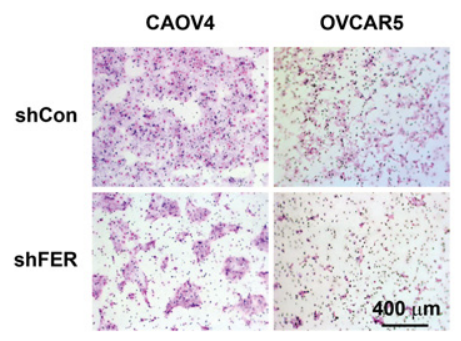

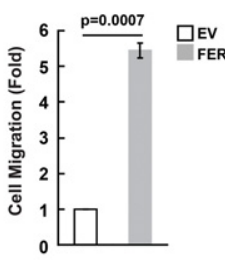

G

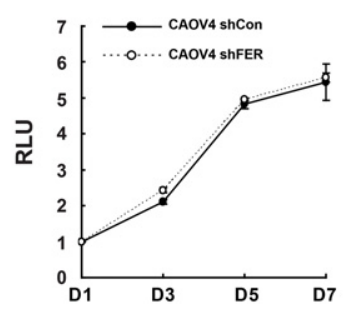

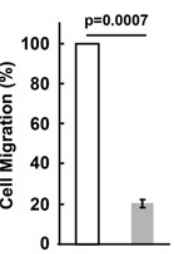

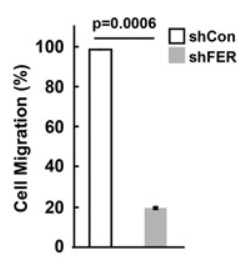

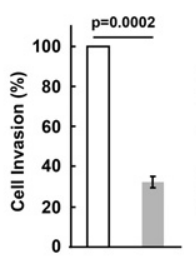

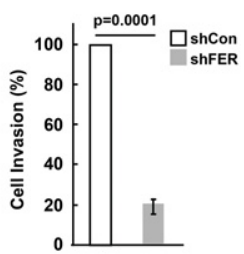

H
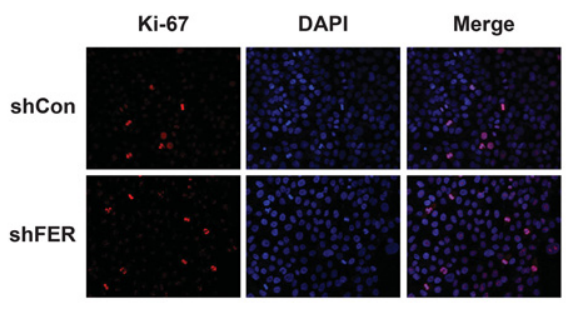

Figure 1. FER was up-regulated in ovarian cancer-derived cell lines and was essential for cell motility and invasiveness. $(A)$ Total cell lysates from two control and 11 ovarian carcinoma-derived cell lines were immunoblotted for FER and loading control actin. $(B)$ HOSE11-12 cells were transiently transfected with either empty vector or FER constructs and immunoblotted for tyrosine phosphorylation of $\beta$-catenin, FER, and a loading control, ERK. $(C)$ The effect of FER overexpression on cell motility was measured by Boyden chamber assay $24 \mathrm{~h}$ after seeding. Representative bright-field images are illustrated, together with quantitation. Mean \pm S.E.M. $n=3$. $(D)$ shRNA knockdown of FER in three ovarian cancer-derived cell lines. $(E, F)$ The effects of FER loss on cell motility $(E)$ and invasiveness $(F)$ were measured by Boyden chamber assay $24 \mathrm{~h}$ after seeding. Representative bright-field images are illustrated, together with quantitation. Mean \pm S.E.M. $n=3 .(G, H)$ Cell growth was assessed by CellTiter-Glo luminescent cell viability assay at the indicated time intervals $(G)$ and by Ki-67 immunostaining $(H)$.

Suppression of FER led to attenuated tyrosine phosphorylation of HGF receptor (HGFR/MET) and inhibition of the downstream SHP2-MAPK signaling pathway

Up-regulation and activation of FER has been reported in multiple cancers, including lung (Rikova et al. 2007), hepatic (Li et al. 2009), prostate (Zoubeidi et al. 2009), breast (Albeck and Brugge 2011), and ovarian cancer (Ren et al.
2012). Its oncogenic role has been implicated in the control of cell motility and invasion, suppression of apoptosis, and drug resistance (Greer 2002; Craig 2012). Nevertheless, due to the limited number of known substrates of FER, the molecular basis for its protumorigenic function is still largely unknown. Given its robust effect on ovarian cancer cell migration and invasion, we examined its downstream effectors/substrates first by measuring changes in the global tyrosine phosphorylation profile. Phosphorylation of a 
band of $\sim 140 \mathrm{kDa}$, which comigrated on SDS-PAGE with the mature form of MET, was markedly diminished in two CAOV4 cell lines in which FER was suppressed with different shRNAs (Fig. 2A). Tandem MET immunoprecipitation and pTyr immunoblotting confirmed the decrease of total MET tyrosine phosphorylation in FER-deficient CAOV4 cells (Fig. 2B). The phosphorylation status of both activation loop phosphorylation sites (Tyr1234 and Tyr1235) and the C-terminal docking site (Tyr1349), the regulation of which by autophosphorylation in trans has been established, were profoundly decreased in the absence of FER (Fig. 2C). This decrease in phosphorylation of MET was observed in all three ovarian cancer cell lines tested (Fig. 2D; Supplemental Fig. S3A) even after HGF treatment, which rules out effects specific to one cell type. Interestingly, the SHP2-MAPK axis downstream from MET, but not PI3K-AKT and SRC, was primarily attenuated upon FER loss (Fig. 2C,D). Activation of the PI3K-AKT pathway is MET-dependent in CAOV4 cells, since MET knockdown with siRNA markedly decreased AKT activation (Supplemental Fig S3B). Furthermore, loss of FER showed no discernable effects on either EGF-induced EGFR-ERK (Fig. 2E) or IL-6-induced STAT3-p38 activation (Fig. 2F), suggesting a specific impact of FER on MET regulation in these cells. In addition, loss of FER in ovarian cancer cells had no apparent impact on the regulation of its known substrates, cortactin and p130CAS, in both basal and HGF stimulation conditions (Supplemental Fig. S3C,D), further suggesting that MET is the major target of FER in these cells.

In an alternative approach, which also helps to exclude potential off-target effects of shRNA, we tested mouse embryonic fibroblasts (MEFs) generated from mice that express a FER-D743R mutant. Asp743 contributes to the conformational stability of the catalytic loop by forming hydrogen bonds with the backbone amide groups of the catalytic loop residues. Mutation of aspartic acid 743 to arginine resulted in inactivation of the FER kinase domain as well as destabilization of the protein (Cole et al. 1999). Consistent with previous findings, we observed that the pTyr immunoreactive band that comigrated with the mature form of MET was lost from the lysate of FER-D743Rexpressing MEFs (Fig. 2G). Tandem MET immunoprecipitation and pTyr immunoblotting further confirmed the decrease of total MET tyrosine phosphorylation in FERD743R MEF cells (Fig. 2G). In particular, tyrosine phosphorylation of the MET activation loop and SHP2 were markedly decreased (Fig. 2H). Together, these results illustrate that this FER-mediated regulation of MET was not restricted to one cell type and occurred in both normal and cancer cells.

\section{The kinase activity of FER and MET were essential for cell motility}

We performed a rescue experiment in FER-D743R-expressing MEFs to address the importance of the kinase activity of FER to its function in cell motility. We established MEF cell lines that expressed either MYC-tagged wildtype or kinase-dead mutant (K592R) FER in the FER-
D743R background to a level of expression similar to that of FER in wild-type MEFs (Fig. 3A). The migration assay confirmed that destabilization-mediated loss of FER resulted in an approximately threefold decrease in cell motility (Fig. 3B,C). Furthermore, wild-type FER rescued the defect in cell migration completely, whereas the kinasedead mutant FER was largely ineffective (Fig. 3B,C).

We examined further whether MET was essential for FER-modulated cell migration in ovarian cancer cells. MET expression was suppressed by two distinct siRNAs in CAOV4 cells in the absence or presence of ectopic FER (Fig. 3D). A wound healing assay was performed to measure the impact of FER and MET on cell motility. The motility of CAOV4 cells in this assay was dramatically decreased upon MET knockdown (Fig. 3E,F). In contrast, overexpression of FER further accelerated cell motility compared with parental CAOV4 control cells; however, this did not compensate for the loss of MET (Fig. 3E,F), which suggests that MET was a critical downstream effector of FER in the regulation of cell migration in ovarian cancer-derived cell lines.

Activation of RAC1-PAK1, the downstream effector of MET in cell motility regulation, was attenuated upon FER loss

MET regulates cell migration mainly by modulating cadherin and integrin adhesion molecules through the RAC1-PAK and RAP1-FAK pathways /Gherardi et al. 2012), respectively. Therefore, we investigated whether these signaling pathways were impaired due to the inactivation of MET upon FER loss in ovarian cancer cells. We observed robustly elevated expression of PAK1, but not PAK2 or PAK4, in most ovarian cancer-derived cells compared with two normal HOSE controls (Supplemental Fig. S4A). We failed to detect any expression of PAK3 in the same cell extracts, probably due to its restricted expression pattern in dendritic cells (Molli et al. 2009). Knockdown of FER dampened the activation of PAK1, illustrated by the decreased phosphorylation of its activating site, Ser144 (Supplemental Fig. S4B). Using a GST pull-down assay with the RAC1-binding domain of PAK1 as bait (Supplemental Fig. S4C), we demonstrated that, in cells lacking FER, this inactivation was associated with decreased binding of RAC1, the direct upstream activator of PAK1.

In addition, we investigated the RAP1-FAK signaling pathway in these cells. Whereas the expression level of FAK was up-regulated in certain ovarian cancer cell lines compared with HOSE controls (Supplemental Fig. S4D), its activation was unchanged in the presence or absence of FER upon HGF stimulation (Supplemental Fig. S4E). Together, these results are consistent with FER playing an important role in regulating MET-induced ovarian cancer cell motility through RAC1-PAK1.

\section{FER bound to and directly phosphorylated MET at} Tyr 1349

To elucidate the molecular mechanism by which FER regulates MET, first we examined, by immunoprecipitation, 
Fan et al.

A

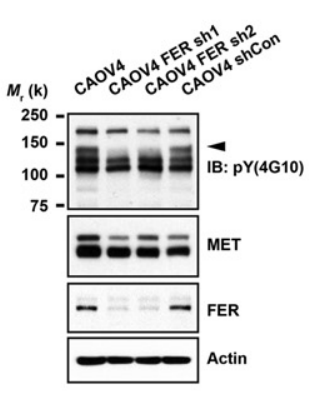

B

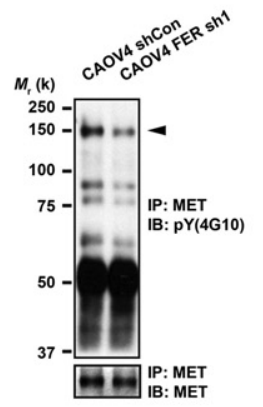

C

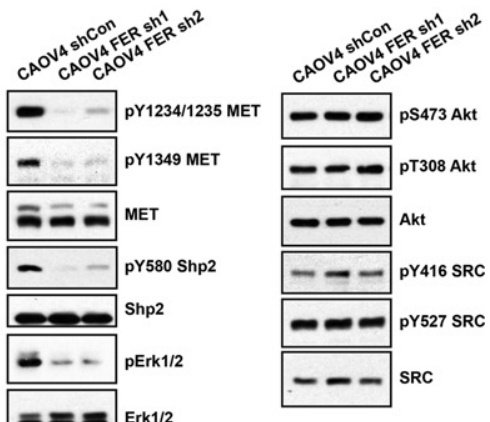

E

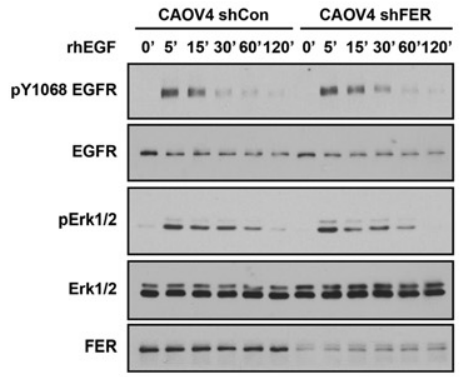

H

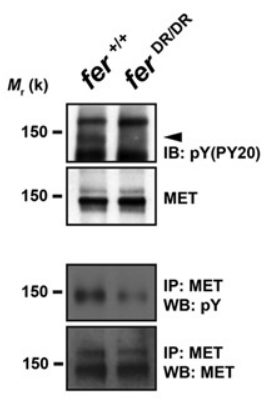

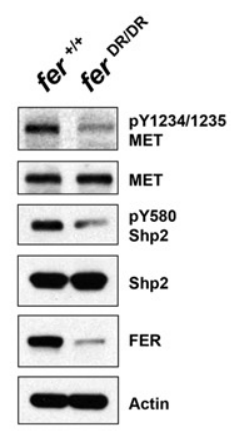

Figure 2. Loss of FER attenuated tyrosine phosphorylation of HGFR (MET) and MET-mediated downstream signaling. (A) Anti-phosphotyrosine antibody immunoblot (4G10) to examine the impact of FER knockdown on tyrosine phosphorylation in CAOV4 cells. The blot was reprobed with antibodies against MET, FER, and the loading control actin. (B) Tyrosine phosphorylation of MET was examined by immunoprecipitation followed by blotting with anti-phosphotyrosine antibody 4G10. The blot was reprobed for MET to indicate equal immunoprecipitation efficiency and loading. $(C)$ CAOV4 cells expressing either control or FER shRNA were lysed and immunoblotted as indicated to measure the activation of MET and MET-regulated downstream signaling pathways. $(D-F)$ Cells were serum-starved and stimulated with recombinant human HGF $(D)$, EGF $(E)$, or IL-6 $(F)$ for the indicated times; lysed; and immunoblotted with the designated antibodies to illustrate the impact of FER deficiency on HGF-, EGF-, or IL-6-induced signaling. (G, top) Anti-phosphotyrosine antibody immunoblot (PY20) to examine the effects of a destabilized FER-D743R mutant on tyrosine phosphorylation in mouse embryonic fibroblasts (MEFs). The position of MET is indicated by an arrowhead. The blot was reprobed for MET. (Bottom) MET was immunoprecipitated from both $\mathrm{Fer}^{+/+}$and $\mathrm{Fer}^{\mathrm{DR} / \mathrm{DR}}$ MEF cell lysates, and tyrosine phosphorylation was examined by immunoblotting with antibody 4G10. (H) $\mathrm{Fer}^{+/+}$and $\mathrm{Fer}^{\mathrm{DR} / \mathrm{DR}}$ MEF cells were lysed and immunoblotted as indicated to illustrate the impact of FER destabilization on MET and MET-mediated downstream signaling pathways. 
A

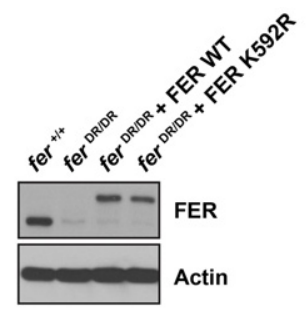

D

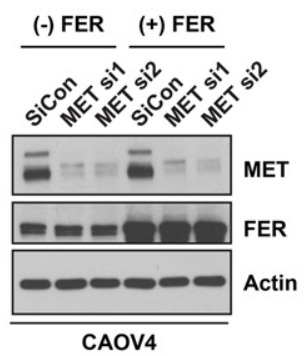

B

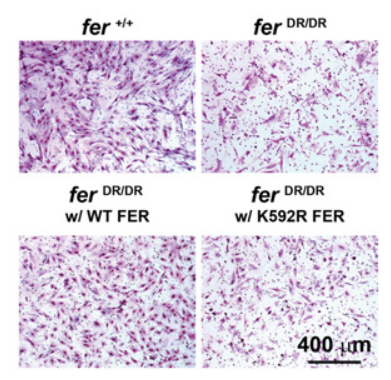

E

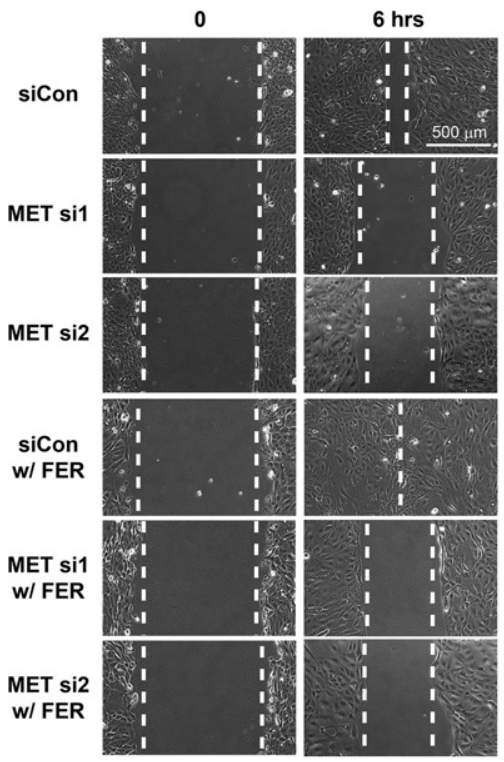

C

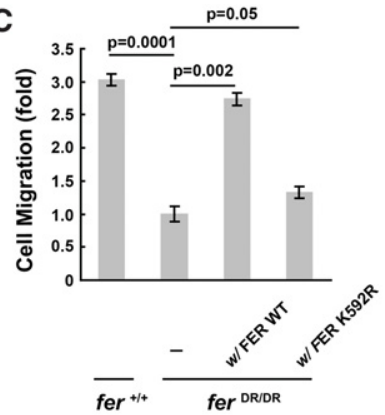

$\mathbf{F}$

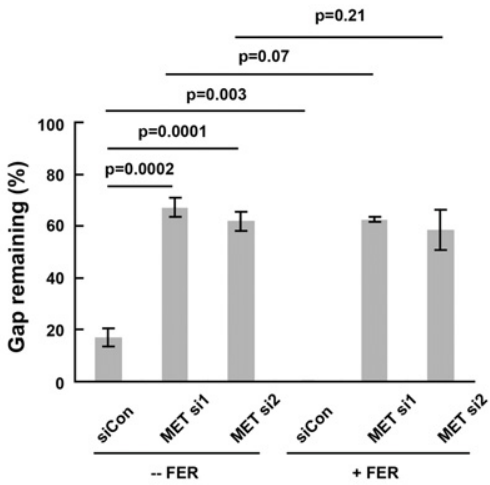

Figure 3. The kinase activity of FER and its downstream effector, MET, were essential for cell motility. (A) MEF cell lysates $\mathrm{Fer}^{+/+}$, $\mathrm{Fer}^{\mathrm{DR} / \mathrm{DR}}$, and $\mathrm{Fer}{ }^{\mathrm{DR} / \mathrm{DR}}$ rescued with either 6xMYC-tagged wild type or the kinase-dead FER-K592R mutant were immunoblotted with antibody against FER to demonstrate comparable expression. Actin was probed as the loading control. $(B, C)$ A Boyden chamber assay was performed on the indicated MEF cells, in which migration was monitored $24 \mathrm{~h}$ after seeding. Representative images are illustrated $(B)$, along with quantitation (mean $\pm \mathrm{SEM} ; n=3)(C)$. $(D)$ Both MET siRNAs and a FER expression construct were delivered as indicated into CAOV4 cells by electroporation. After $48 \mathrm{~h}$, the expression levels of MET and FER were measured by immunoblotting, with actin as a loading control. $(E, F)$ Forty-eight hours after electroporation and seeding, a wound healing assay was performed on the cell lines indicated in $D$. Wound recovery was recorded $6 \mathrm{~h}$ after scratch injury. Representative images are illustrated $(E)$, together with quantitation $($ mean \pm $\mathrm{SEM} ; n=3)(F)$.

whether there was any physical interaction between them. We detected ectopically expressed FER and MET in the same complex (Fig. 4A). Furthermore, this interaction was also detected at the endogenous level of expression in three ovarian cancer-derived cell lines tested (Fig. 4B). To address the potential significance of this interaction in relaying signals, we introduced a mutant form of MET (mATP MET, with a K1003R mutation), which is disabled in endogenous ATP loading and autophosphorylation. We observed that wild-type FER promoted phosphorylation of the MET MATP mutant at Tyr1349 (Fig. 4C), whereas kinase-dead mutant (FER K592R) or SH2 mutant FER did not. In contrast, we did not detect phosphorylation of the activation loop Tyr residues 1234 and 1235 of MET by FER (Fig. 4C). In addition, we also observed increased wild-type MET Tyr 1349 phosphorylation in the presence of either wild-type or mutant FER, likely due to the increased level of wild-type MET ex- pression and autophosphorylation. Due to the lack of a reliable phospho-specific antibody, we were unable to measure phosphorylation of Tyr1356 in MET. The interaction was not attenuated by either mutations in FER that affect its kinase activity or SH2 domain recognition or mutations in MET that abolish overall autophosphorylation or phosphorylation of specific tyrosine residues (1349 and/or 1356) (Fig. 4D,E).

Downstream, we observed enhanced colocalization of GRB2 and mATP MET when FER was expressed (Supplemental Fig. S5). Furthermore, FER enhanced the interaction between MATP MET and GAB1, and this interaction was abolished when Tyr1349 in MATP MET was mutated to Phe (Fig. 4F). Also, we observed increased phosphorylation of Tyr580 of SHP2 and activation of ERK signaling in the presence of FER (Fig. 4C). Neither kinasedead nor SH2 mutant forms of FER could activate the SHP2-ERK signaling pathway to the level observed with 
Fan et al.

A

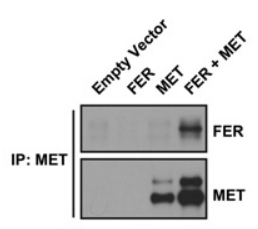

C

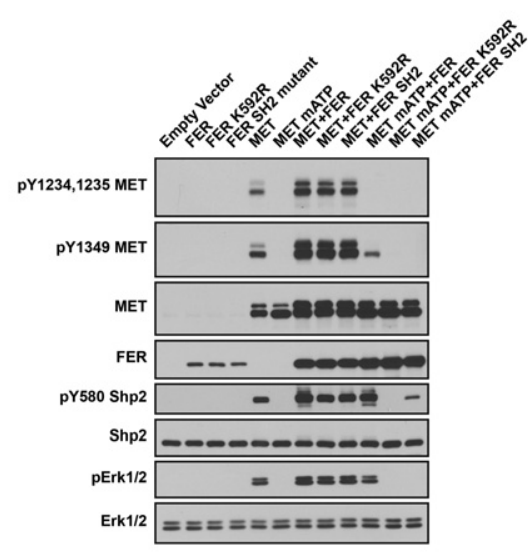

B
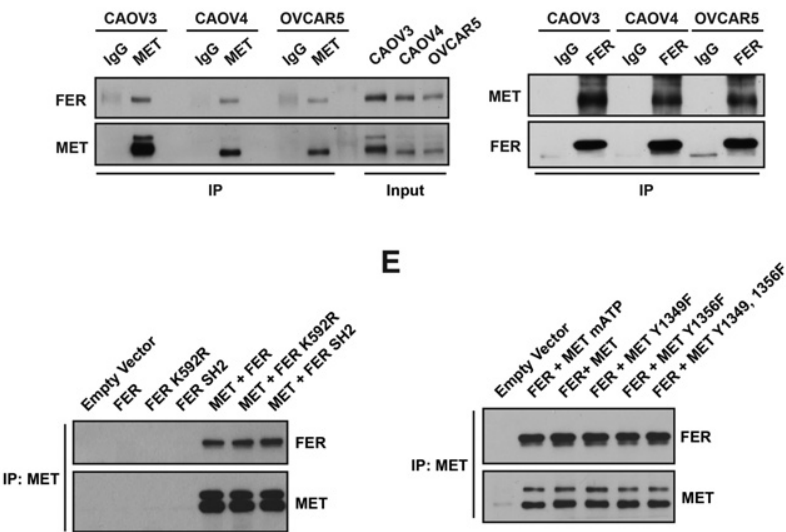

F

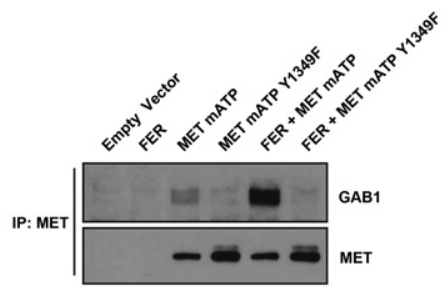

G

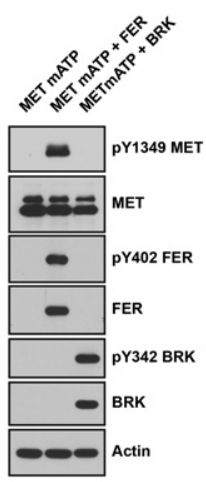

$\mathbf{H}$

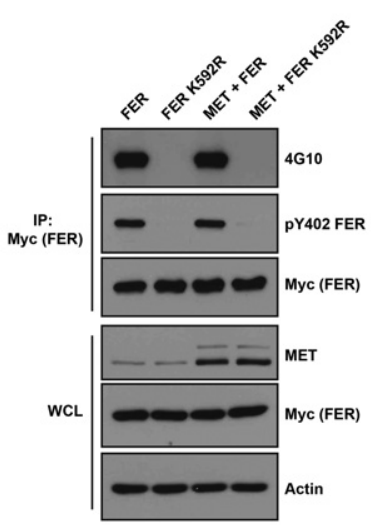

I

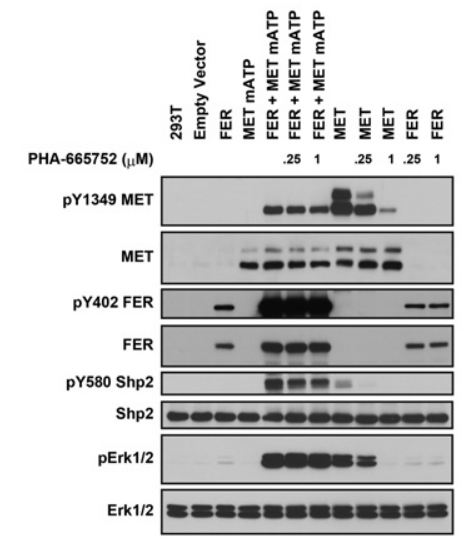

Figure 4. FER bound to and phosphorylated MET at Tyr1349. (A) After transient transfection in 293T cells, MET was immunoprecipitated and probed for association with FER (left) and vice versa (right). (B) Endogenous MET was immunoprecipitated from CAOV4, CAOV3, and OVCAR5 ovarian cancer cells and probed for association with FER (left) and vice versa (right). (C) 293T cells were transiently transfected with the indicated constructs, lysed, and immunoblotted as indicated to illustrate the phosphorylation of MET by FER and its impact on downstream SHP2-ERK signaling. (D) MET was coexpressed with either wild-type or mutant forms of FER (kinase-dead K592R or SH2 mutant) in 293T cells to compare the effects of mutations in FER on its association with MET. (E) FER was coexpressed with either wild-type or Tyr $\rightarrow$ Phe mutants of MET (Y1349F, Y1356F, or YY1349,1356FF) in 293T cells to compare the effects of the MET point mutations on its association with FER. (F) FER was expressed alone or with either mATP or mATP Y1349F mutant forms of MET in 293T cells. MET was immunoprecipitated, and the association with GAB1 in each sample was assessed by immunoblotting. (G) 293T cells were transiently transfected with MET mATP alone or together with either FER or BRK, and the phosphorylation of MET on Tyr1349 was assessed by immunoblotting. (H) 6xMYC-tagged wild-type or inactive K592R FER was expressed alone or cotransfected with MET, immunoprecipitated with anti-MYC antibody, and probed for tyrosine phosphorylation with either 4G10 (global Tyr phosphorylation) or pTyr402-FER-specific antibodies. (I) Transfected 293T cells were treated with or without MET inhibitor PHA-665752 (4 h), as indicated, and the cell lysates were immunoblotted with the designated antibodies to illustrate the effect of the small molecule inhibitor on MET phosphorylation and downstream SHP2-ERK signaling.

wild-type FER (Fig. 4C). Of note, FER activated signaling downstream from mATP MET to a level that was comparable with that of wild-type MET in terms of SHP2 phos- phorylation and ERK activation (Fig. 4C). Consistent with their coimmunoprecipitation, we also observed the colocalization of ectopically expressed FER and MET 
mATP (Supplemental Fig. S5). In addition, these effects on MET were FER-specific, since other nonreceptor PTKs such as BRK/PTK6, although active, did not phosphorylate MET at Tyr1349 (Fig. 4G)

The kinase activity of FER has been shown to be affected by multiple stimuli, including growth factors EGF (Kim and Wong 1995) and PDGF (Kim and Wong 1995; Craig et al. 2001), hydrogen peroxide (Sangrar et al. 2007), ECM-integrin signaling (Ivanova et al. 2013), and the PLD-PA pathway (Itoh et al. 2009); therefore, we tested whether HGF-MET could also be an upstream modulator of FER. MYC-tagged wild-type or kinase-dead FER was transiently coexpressed with MET in 293T cells, and tyrosine phosphorylation of FER was compared following immunoprecipitation with MYC antibody 9E10. We did not detect tyrosine phosphorylation (either overall or site-specific, Tyr402) of kinase-inactive FER in the presence of MET (Fig. 4H), suggesting that the activity of FER was not regulated by $\mathrm{MET}$.

In addition, we tested whether FER-mediated transphosphorylation could be blocked by PHA-665752, a potent, selective, ATP-competitive inhibitor of MET (Christensen et al. 2003). As shown in Figure 4I, PHA665752 robustly inhibited the kinase activity of MET and its downstream SHP2-ERK signaling in a dose-dependent manner. The selectivity of its inhibition of MET over FER was indicated by the fact that both concentrations of inhibitor had no effect on autophosphorylation of FER. Furthermore, neither transphosphorylation of MET mATP mutant by FER nor downstream SHP2-ERK activation was not affected by PHA-665752. This observation illustrates that the activity of MET was not required for FER-mediated transphosphorylation.

\section{FER formed a complex with GAB1 via MET and phosphorylated GAB1 at Tyr627}

Considering that FER phosphorylated kinase-dead MET at Tyr1349, which was accompanied by specific activation of the SHP2-ERK pathway, we examined the mechanism of this signal selectivity. It has been reported that GAB1 could bind to MET directly and that this interaction was dependent on Tyr1349 (Weidner et al. 1996; Nguyen et al. 1997). In addition, GAB1 possesses multiple tyrosine residues, which, upon phosphorylation, provide docking sites for different signaling components, including regulatory subunit p85 of $\mathrm{PI} 3 \mathrm{~K}$ and SHP2. Interestingly, binding of SHP2 to GAB1 facilitates the dephosphorylation of p85-binding sites, ensuring MEK-ERK activation exclusively (Zhang et al. 2002). To pursue this, we tested first whether the global tyrosine phosphorylation of GAB1 was affected upon FER expression. We confirmed that tyrosine phosphorylation of GAB1 was increased by wild-type but not inactive K592R FER (Fig. 5A). We also detected four other pTyr proteins in the GAB1 immunocomplex following FER expression (at $\sim 140,90,72$, and $68 \mathrm{kDa})$, suggesting either more than one substrate of FER or an indirect impact of FER through GAB1 phosphorylation. Furthermore, experiments using a phospho-specific antibody suggested that Tyr627 of GAB1 was phosphorylated by FER (Fig. 5B). Consistently, the phosphorylation of this site was diminished in FER-deficient CAVO4 cells (Fig. 5C). Of note, it has been reported that Tyr627 of GAB1, when phosphorylated, is responsible for SHP2 recruitment and RAS-MEK-ERK activation (Zhang et al. 2002). We observed consistently the FER-mediated positive regulation of Tyr580 phosphorylation in SHP2 (Fig. 5B,C) and ERK (Fig. 5B) activation, leaving the AKT signaling pathway unchanged (Fig. 5B). We observed FER-mediated phosphorylation of Tyr627 in GAB1 in CAOV4, CAOV3, and OVCAR5 cells (Fig. 5D), illustrating that this effect was not restricted to one specific cell line. Furthermore, the extent of phosphorylation of Tyr627 in GAB1 was decreased in FER D743R transgenic MEFs (Fig. 5E), ruling out possible RNAi off-target effects. Loss of GAB1 dramatically decreased the activation of PAK1, suggesting an indispensable role of GAB1 regulating downstream PAK1-RAC1 activation (Fig. 5F).

To investigate whether there was any physical association between FER and GAB1, we conducted immunoprecipitation experiments in all three ovarian cancer cell lines, examining the endogenous levels of the proteins. Interestingly, compared with IgG control antibody, we detected GAB1 in the immunocomplex precipitated by the FER antibody and vice versa (Fig. 5G). To test whether this interaction was direct or MET-mediated, we expressed FER and MET mATP either alone or combined in $293 \mathrm{~T}$ cells and then immunoprecipitated GAB1. FER was observed only in GAB1 immunoprecipitates in the presence of MET MATP, and the presence of FER coincided with phosphorylation of the GAB1-interacting motif Tyr1349 (Fig. 5H). This suggests an indirect interaction between GAB1 and FER, with a "scaffold" role of kinase-dead MET to nucleate these signaling components and facilitate downstream pathway activation even without the kinase activity of MET.

LOSS of FER impaired the metastasis of ovarian cancer cells to the lung through MET inactivation

Our observation that FER-deficient ovarian cancer cells showed reduced migration and invasion prompted us to investigate its role further in vivo. We adopted a xenograft mouse model with subcutaneous injection of either shCon or shFER CAOV4 cells to evaluate whether expression of FER affected the metastasis of ovarian cancer cells (Fig. 6A). Five weeks after inoculation, the mean subcutaneous tumor volume in each group reached $\sim 250 \mathrm{~mm}^{3}$, with no significant difference in the presence or absence of FER (Fig. 6B). In addition, we did not observe signs of metastasis in any of the mice at that time (Fig. 6A). In order to relieve the tumor burden as well as provide a clean background to monitor the outgrowth of metastatic lesions, we performed surgery to remove all of the subcutaneous tumors. We did not see a significant difference in tumor weight in all three groups (Fig. 6C), consistent with the cell-based assays (Fig. 1G,H), suggesting that FER had no impact on ovarian cancer cell proliferation. In addition, we achieved complete removal of the subcutaneous 
A

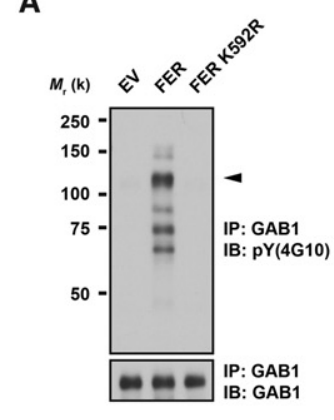

C

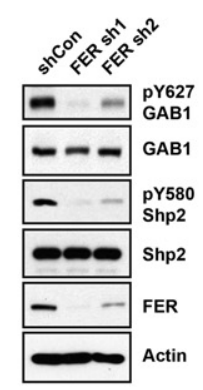

B

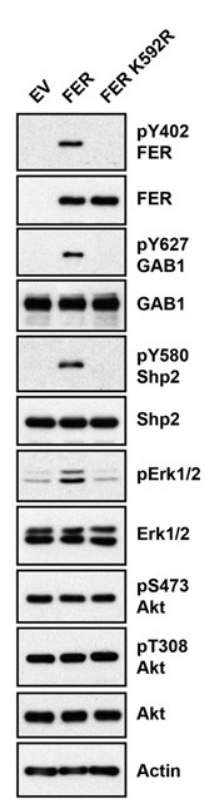

D

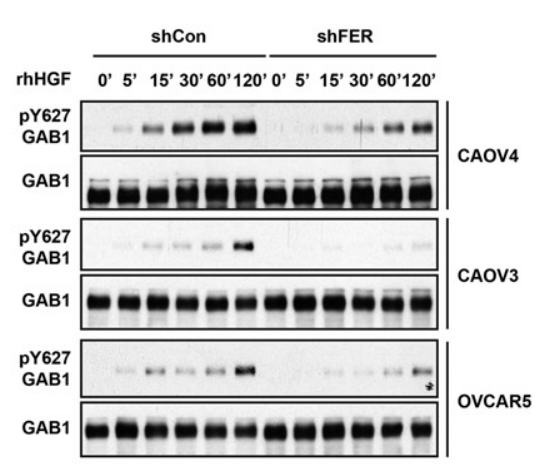

G

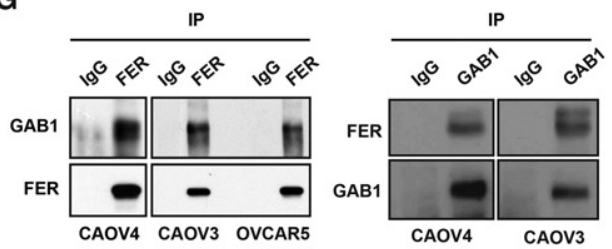

E

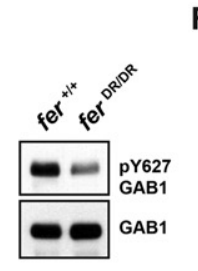

F

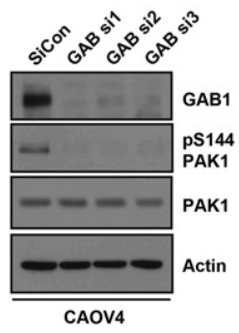

H

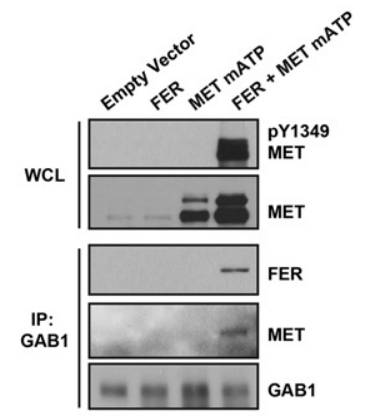

Figure 5. FER formed a complex with GAB1 via MET and phosphorylated GAB1 at Tyr627. 293T cells were transiently transfected with either wild-type FER or a kinase-dead FER-K592R mutant. (A) Tyrosine phosphorylation of GAB1 was examined by immunoprecipitation and blotting with anti-phosphotyrosine antibody 4G10. (B) The whole-cell lysates were immunoblotted as indicated to show the increased tyrosine phosphorylation of GAB1 and SHP2 and the impact on downstream signaling. (C) Tyrosine phosphorylation of GAB1 and SHP2 was compared in CAOV4 cells expressing either control or FER targeted shRNAs. $(D)$ Cells were serum-starved and stimulated with hHGF for the indicated times, lysed, and immunoblotted with both pTyr627 and total GAB1 antibodies to demonstrate FER-regulated GAB1 phosphorylation. (E) Phosphorylation status of Tyr627 of GAB1 in $\mathrm{Fer}^{+/+}$and $\mathrm{Fer}^{\mathrm{DR} / \mathrm{DR}} \mathrm{MEF}$ cells. (F) Control or GAB1 siRNAs were delivered into CAOV4 cells by electroporation. After $48 \mathrm{~h}$, the expression levels of GAB1 and activation of PAK1 were measured by immunoblotting. $(G)$ Endogenous FER was immunoprecipitated from CAOV4, CAOV3, and OVCAR5 ovarian cancer cells, and its association with GAB1 was examined by immunoblotting (left) and vice versa $(r i g h t) .(H)$ Endogenous GAB1 was immunoprecipitated from lysates of 293 cells transfected with FER and the MET mATP mutant alone or together. The association of FER and MET was assessed by immunoblotting.

tumor, with no luminescence signal in imaging $4 \mathrm{~d}$ after surgery (Fig. 6A).

We continued to monitor the incidence of tumor metastasis, and, from day 53 , which was $\sim 2.5$ wk after surgery, we began to detect a signal in the lungs of mice in the shCon group but not from the shFER groups (Fig. 6A). This observation was consistent throughout the whole course of the experiment, until we sacrificed all of the mice at the end of week 10 . We collected the lung, liver, and bone from each mouse and tested the intensity and incidence of the luminescence signal. We detected the signal from the lung only in the control shCon group (Fig. 6A); furthermore, both the number of nodules (Fig. 6D) and the area (Fig. 6E) of lung metastases were significantly higher in the shCon group as compared with both FER-deficient groups. H\&E staining further confirmed the frequency as well as outgrowth properties of metastasis nodules in lung sections from shCon mice (Fig. 6F), strongly supporting the role of FER in ovarian tumor metastasis in vivo.

In order to examine potential changes in HGF-MET signaling in the presence and absence of FER, we performed immunohistochemistry staining on subcutaneous tumors. We did not observe changes in cell morphology in subcutaneous tumors by $\mathrm{H} \& \mathrm{E}$ staining (Fig. 6G). Antibody staining confirmed the clear knockdown of FER throughout the xenograft experiment (Fig. 6G). It is important to note that the signal of MET activation (pTyr1349 and pTyr1234/1235) was significantly stronger in the shCon group compared with the shFER groups (Fig. 6G). Overall, this analysis provides compelling evidence to suggest a prometastatic role of FER in ovarian tumorigenesis, suggesting that its inhibition may potentially attenuate metastasis.

\section{Loss of FER attenuated metastasis of ovarian cancer cells injected into the peritoneal cavity}

A prominent feature of ovarian cancer is that the tumor cells may be transported throughout the peritoneal cavity to adjacent organs by normal peritoneal fluid, which accelerates metastasis. In order to recapitulate this situation more accurately, we adopted a mouse model with intraperitoneal injection.

CAOV4 cells expressing either control shRNA (shCon; $n=6)$ or shRNAs targeting FER (sh1 $[n=7]$ and $\operatorname{sh} 2[n=6])$ (Fig. 7A) were injected, and necropsy procedures were performed 4 wk after inoculation. Representative images 
A

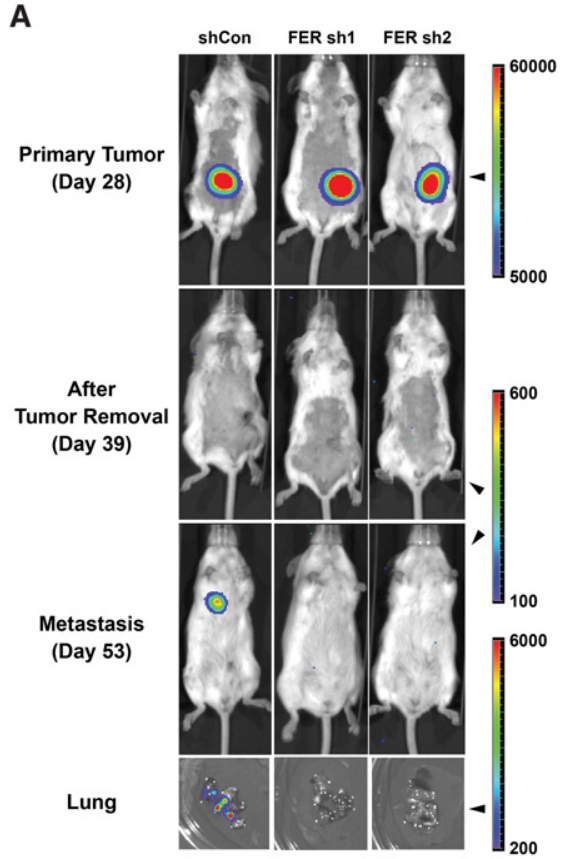

$\mathbf{F}$

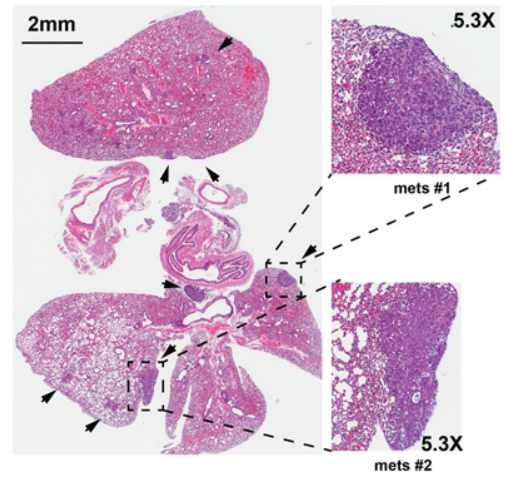

B

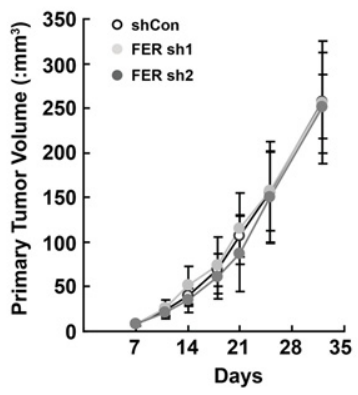

D

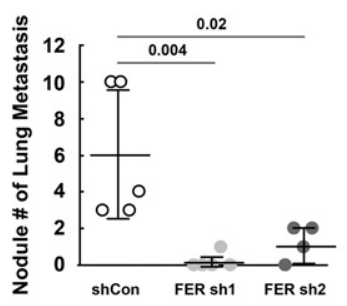

C

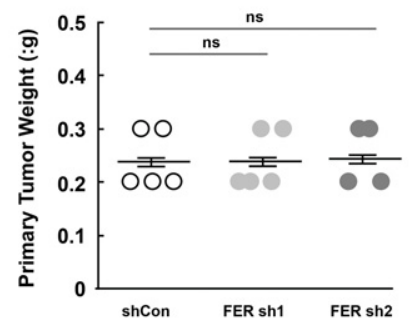

E

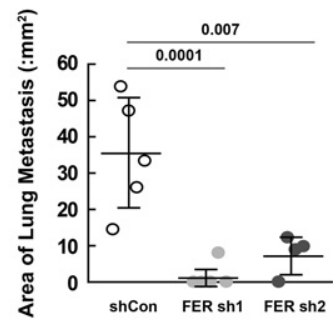

G

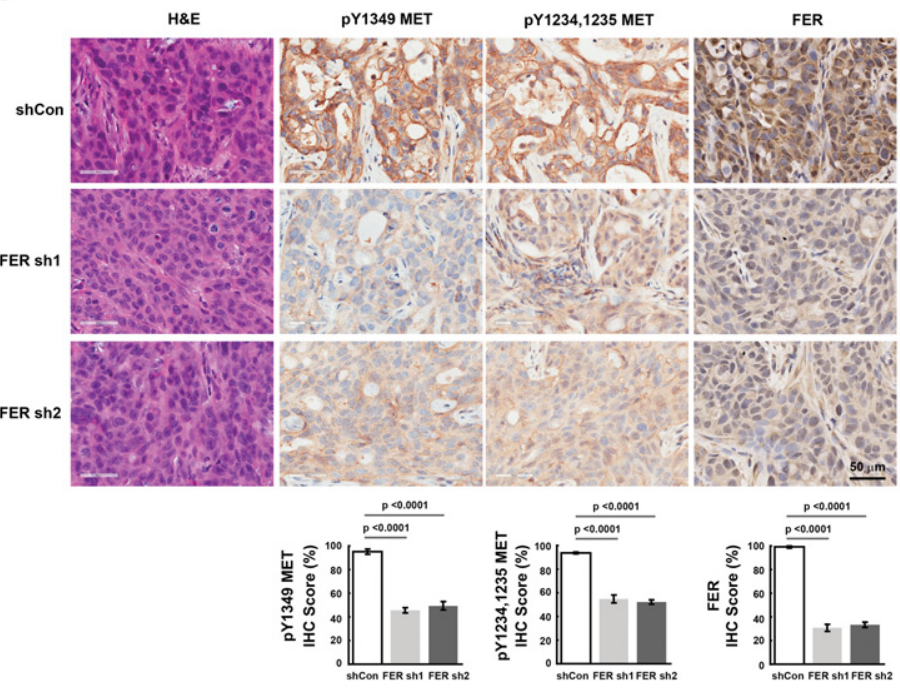

Figure 6. Loss of FER reduced lung metastasis burden of ovarian cancer cell xenografts with inactivation of MET. (A) At the indicated time points, mice injected with CAOV4 cells expressing either shCon $(n=5)$, FER sh1 $(n=5)$, or FER sh2 $(n=4)$ were imaged using IVIS bioluminescence imaging. Representative images are shown. $(B, C)$ Measurements of subcutaneous tumor volume $(B)$ and weight $(C)$ for mice injected with either shCon, FER sh1, or FER sh2 CAOV4 cells. $(D)$ Metastasis lesion count (naked eye as well as IVIS imaging confirmation) with mice injected with either shCon, FER sh1, or FER sh2 CAOV4 cells. (E) Metastasis lesion area measurement with mice injected with either shCon, FER sh1, or FER sh2 CAOV4 cells. $(F)$ Representative H\&E staining of lung sections from mice with metastatic lesions that express the control shRNA (shCon). (G) H\&E and immunohistochemistry staining (pTyr MET and FER) of subcutaneous tumor sections from mice injected with CAOV4 cells expressing either shCon, FER sh1, or FER sh2. The immunohistochemistry image was scored with Aperio software.

from mice intraperitoneally injected with control shRNAexpressing CAOV4 cells are illustrated in Supplemental Figure S6. Consistent with the subcutaneous injection mouse model, the ability of CAOV4 cells to metastasize to surrounding tissue/organs, including the peritoneal wall, diaphragm, omentum, mesentery, ovary, stomach, and liver, was greatly decreased in the absence of FER (Fig. 7B-H; Supplemental Fig. S7). Metastatic tumor quan- tifications from all three groups are summarized in the Supplemental Table.

Expression of FER was elevated and inversely correlated with progression-free survival in ovarian cancer patients

In support of these functional studies of FER in ovarian cancer cell lines, we searched the Human Protein Atlas 
Fan et al.

A

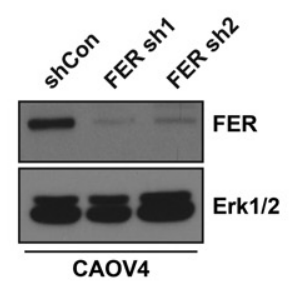

E

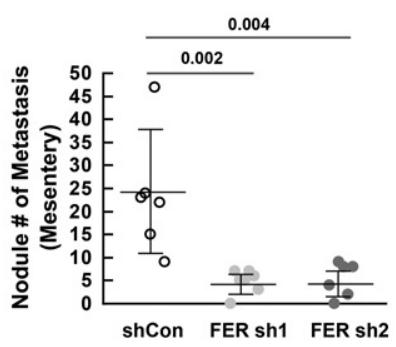

B

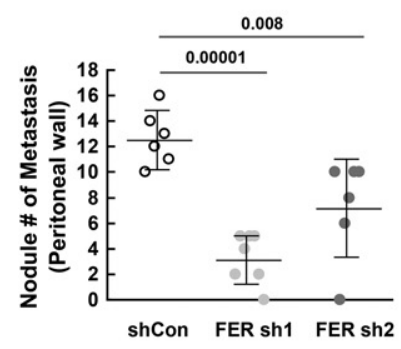

F

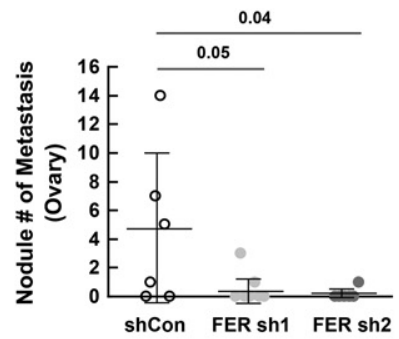

C

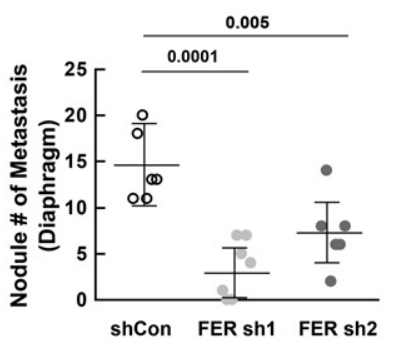

G

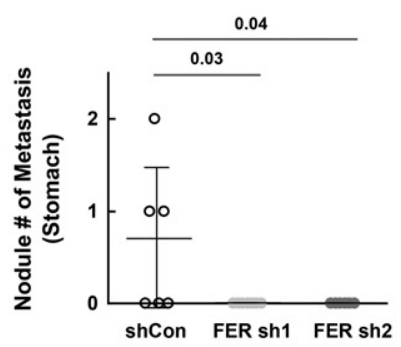

D

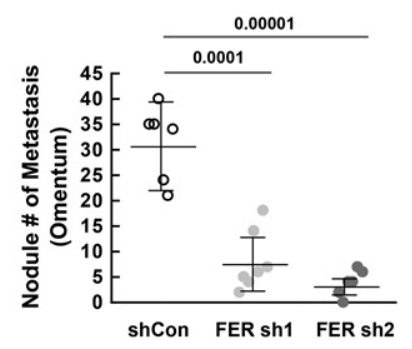

H

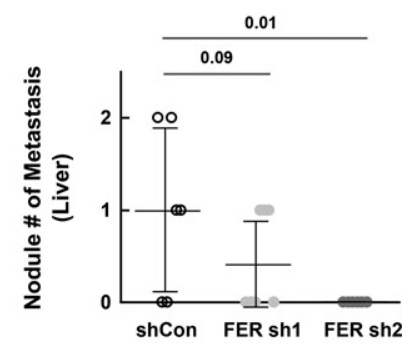

I

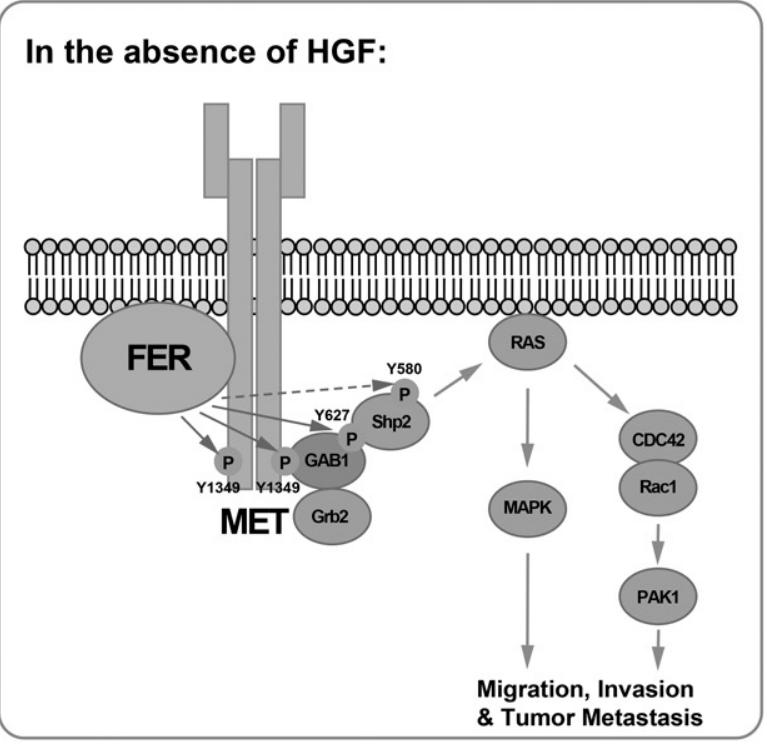

Figure 7. Loss of FER reduced metastasis of ovarian cancer cells via the peritoneal cavity. $(A)$ Knockdown efficiency was confirmed by immunoblotting in both FER shRNA CAOV4 cell lines prior to intraperitoneal injection. $(B-H)$ Mice were injected intraperitoneally with $5 \times 10^{6}$ CAOV4 cells expressing either shCon $(n=6)$, FER sh $1(n=7)$, or FER sh2 $(n=6)$. After 4 wk, necropsy procedures were performed, and the ability of CAOV4 cells to metastasize to surrounding tissue/organs, including the peritoneal wall $(B)$, diaphragm $(C)$, omentum $(D)$, mesentery $(E)$, ovary $(F)$, stomach $(G)$, and liver $(H)$, were assessed. $(I)$ Working model: In the absence of the ligand HGF, FER directly phosphorylated MET, GAB1, and possibly SHP2. This led to the activation of SHP2-MAPK and RAC1-PAK1 signaling downstream from MET to potentiate the motility and invasiveness of ovarian cancer cells.

to compare the protein expression level of the kinase between normal ovaries and malignant ovarian carcinomas. Consistent with our findings, we observed high expression of FER in human ovarian cancer samples; in contrast, the kinase was essentially undetectable in normal ovarian tissue but was present in ovarian follicles (Supplemental Fig. S8A).
We analyzed the clinical data from over a thousand ovarian cancer patients (http://www.kmplot.com) in order to investigate further a relationship between FER expression and tumor metastasis. The data indicate that expression of FER was inversely correlated with progression-free survival (Supplemental Fig. S8B). The extent of separation between low and high expression was similar 
to VCAM1 (Supplemental Fig. S8C), a known metastasis gene in ovarian cancer (Slack-Davis et al. 2009).

\section{Discussion}

In this study, we demonstrated that expression of the nonreceptor PTK FER was elevated in malignant ovarian tumors and was inversely correlated with progression-free survival. In ovarian cancer cell lines, we observed that the levels of FER were elevated relative to those in immortalized normal surface epithelial cells and that suppression of FER attenuated the enhanced motility and invasive properties of these cancer cells. Mechanistically, we demonstrated that FER was an integral component of a novel pathway that underlies ligand-independent signaling downstream from the receptor PTK MET. In particular, FER phosphorylated a signaling site, Tyr1349, in MET, which enhanced activation of RAC1/PAK1 and promoted a kinase-independent scaffolding function that led to recruitment and phosphorylation of GAB1 and the specific activation of the SHP2-ERK signaling pathway (Fig. 7I). Overall, this analysis provides new insights into signaling events that underlie metastasis in ovarian cancer cells, consistent with a prometastatic role of FER and highlighting its potential as a novel therapeutic target for metastatic ovarian cancer.

Given the pathological role of HGF-MET signaling in tumor growth and metastasis, it has been the subject of intense effort to develop various strategies to inhibit the receptor activation and downstream signaling (Comoglio et al. 2008). This includes small molecule inhibitors of its PTK function, particularly by competing with ATP binding. Alternatively, truncated forms of HGF (namely, NK2 or NK4) have been developed to compete for receptor binding without fully activating its tyrosine kinase function. Finally, anti-HGF-neutralizing antibodies have been generated with the goal of lowering the concentration of functional MET ligand in the microenvironment. A common feature of these approaches is the focus exclusively on HGF-dependent MET activation. In contrast, in this study, we demonstrated that Tyr1349, one of the Cterminal signaling sites of MET, was a novel substrate of the PTK FER. The evidence presented here also argues that this ligand- and autophosphorylation-independent activation of MET played an essential role in sustaining tumorigenic signaling downstream from the receptor. As such, this activation mechanism was insensitive to the potent, active site-directed MET inhibitor PHA665752. In fact, a fourth category of inhibitor, involving a peptide that interferes with the C-terminal docking site of MET and which has been shown to display greater inhibitory effect and toxicity tolerance than the MET inhibitor PHA-665752 (Cantelmo et al. 2010; Cho et al. 2013), becomes a more attractive strategy in this context. Considering the data presented here, it is possible that combinations of agents that block both liganddependent and ligand-independent activation of MET may be the most effective strategies for therapeutic intervention.
Aberrant up-regulation and activation of FER has been reported in a number of different cancers. Using an unbiased and global phosphoproteomic approach, the Comb group (Ren et al. 2012) observed activation of FER in 15 out of $69(21.7 \%)$ ovarian tumors, whereas the ratio in normal controls is one out of $19(5.2 \%)$. Several receptors have been identified as upstream activators of FER, including EGFR (Kim and Wong 1995), PDGFR (Kim and Wong 1995; Craig et al. 2001), and integrin (Ivanova et al. 2013). In addition, STAT3 (Priel-Halachmi et al. 2000), cortactin (Kim and Wong 1995; Craig et al. 2001; Sangrar et al. 2007), and Rac GTPase regulators (Fei et al. 2010; Ahn et al. 2013), the functions of which are closely related to tumor progression and metastasis, have been identified as substrates of FER. Interestingly, through an unbiased kinome screening, Fukuda's group (Yoneyama et al. 2012) has identified FER as a key negative regulator of laminin-binding glycan, expression of which profoundly attenuates tumor cell migration. Mechanistically, they found that FER-STAT3 signaling suppresses the transcription of several glycosyltransferases, which are required for laminin-binding glycan synthesis. Recent studies also suggested a role of FER in resistance to the anti-cancer agent quinacrine, an effect that was mediated by an EGF-dependent activation of the NF- $\mathrm{kB}$ pathway (Guo and Stark 2011). We found that FER was also upregulated in a panel of ovarian carcinoma-derived cell lines as well as human ovarian tumor samples, and its elevation inversely correlated with progression-free survival, including after chemotherapy, in ovarian cancer patients (Supplemental Fig. S8). Five-year survival rates are $90 \%$ and $70 \%$, respectively, for women diagnosed with stage I or II ovarian cancer. Unfortunately, due to the lack of a reliable and accurate screening test for the early detection of this disease, $<35 \%$ of women are diagnosed before stage III, and five-year survival for stage III or IV is $<25 \%$. Therefore, it is not surprising that Kaplan-Meier curves display a sharp negative slope from 0 to 24 mo after diagnosis, with both low and high expression of FER, a situation similar to that observed with the established metastasis-promoting gene VCAM1 in ovarian cancer. Nevertheless, it is clear that patients with low FER expression displayed a better prognosis.

Unlike PTKs of the SRC and ABL family, the activation mechanism of FER in cancer has yet to be fully elucidated. There is evidence to indicate that FER directly associates with receptor proteins through its $\mathrm{SH} 2$ domain (Kim and Wong 1995). The resolution of the structure of the SH2 kinase domain fragment of FES, the other member of the FER family, revealed an important interface that was critical for allosteric regulation of the kinase by the $\mathrm{SH} 2$ domains, with FES activation occurring only upon ligand binding to its SH2 domain (Filippakopoulos et al. 2008). Considering the conservation of these critical interface residues between FER and FES, it is likely that activation of FER also uses its SH2 domain. Interestingly, our results demonstrated specificity in the effects of FER on MET and selectivity for activation of SHP2-MAPK rather than PI3K-AKT or SRC downstream signaling pathways (Fig. 2). Consistent with the report from the Mochizuki group 
(Kogata et al. 2003), we found that tyrosine phosphorylation of GAB1-in particular Tyr627, the major docking site for the SH2 domain of SHP2-was robustly increased in the presence of FER (Fig. 5). It is possible that the negative effect of SHP2 on PI3K activation via dephosphorylation of GAB1 p85-binding sites (Zhang et al. 2002) contributes to the activation of ERK MAPK following FER-mediated GAB1 tyrosine phosphorylation and SHP2 recruitment.

It is also important to note that the MET mutant that was deficient in ATP binding, although catalytically inactive, behaved like a "scaffold protein" to provide a platform for nucleating signaling components, including FER and GAB1, which facilitated the tyrosine phosphorylation of GAB1 as well as propagation of MAPK downstream signaling. This observation reinforces the concept that targeting the enzymatic activity of RTKs alone may not be sufficient in cancer treatment. In a pioneering study in this area, to elucidate the mechanisms underlying resistance to small molecule MET inhibitors, Park and colleagues (Lai et al. 2014) demonstrated that STAT3 and ERK pathways promote MET-dependent proliferation and MET-independent gastric cancer cell survival, respectively. Interestingly, although several reports supported the direct MET-dependent tyrosine phosphorylation of STAT3, other MET-independent regulators of STAT3 were also reported, with FER being among them (Priel-Halachmi et al. 2000). In addition, Park and colleagues (Lai et al. 2014) illustrated the importance of ERK reactivation in promoting cell survival in the absence of MET activity, and combination treatments with both MET and MEK inhibitors showed improved efficacy compared with either alone. Considering the novel role of kinase FER in both MET and GAB1 tyrosine phosphorylation and downstream ERK activation demonstrated in this study, it is possible that FER may play a broader role in mediating the activation of ERK in other cancer contexts.

The FES and FER proteins represent a unique family of non-RTKs, distinguishing themselves from other tyrosine kinases by an N-terminal FES/FER/CIP4 homology/Bin1/ Amphiphysin/RVS (F-BAR) lipid-binding domain (Greer 2002; Craig 2012). A function in the regulation of cytoskeletal rearrangement, cell polarity, vesicular trafficking, and endocytosis has been suggested for F-BAR domains. Unlike other F-BAR-containing proteins such as CIP4 or FBP17, the capacity of FER to promote deformation of protein-free liposomes into tubules is much weaker (Tsujita et al. 2006). However, it has been shown that the F-BAR domain along with the F-BAR extension domain (FX) of FER could bind specifically to, and be activated by, phosphatidic acid (PA) in the plasma membrane and that this PLD-PA-mediated regulation of FER plays a positive role in cell migration (Itoh et al. 2009). In addition, our published results demonstrate that ligand-induced endocytosis of RTK EGFR is suppressed in the presence of FER (Sangrar et al. 2015). This suggests that FER may exert another tier of regulation on MET as well augment the kinase activity of the receptor. In fact, upon down-regulation, the activation loop of MET is dephosphorylated and inactivated by an ER-anchored protein tyrosine phosphatase, PTP1B. Interestingly, we reported previously that there was a decrease in expression of PTP1B in all 11 tested ovarian cancer cell lines compared with the two normal controls (Fan et al. 2013, 2015), further supporting the idea that MET-dependent signals may be augmented at the level of both enhanced phosphorylation and activation as well as attenuated dephosphorylation and inactivation.

In summary, we report a novel mode of HGF-independent regulation of MET by the non-RTK FER. Importantly, activation of MET by this mechanism would not be inhibited effectively by the conventional MET-directed inhibitors that are the current focus of research. The implications of this study are that simultaneous targeting of FER together with MET may result in more effective treatment for ovarian cancer. Although no specific inhibitor of FER has been reported as yet, the recent success of inhibitor screens targeting the other family member kinase FES (Hellwig et al. 2012) suggest that it may be possible to exploit this strategy in the near future.

\section{Materials and methods \\ Cell culture}

Ovarian cancer cell culture conditions are described in Fan et al. (2013, 2015).

\section{RNAi}

shRNA knockdown of FER was established in CAVO4, CAOV3, and OVCAR 5 by lentiviral infection following puromycin selection. Detailed protocols are described in Fan et al. (2015). The shRNAs used were FER shRNA\#1 seq (5'-GCAGAAAGTTTGC AAGTAATG-3') and FER shRNA\#2 seq (5'-GCCAAGGAAC GATACGACAAA-3')siRNAs targeting MET were purchased from Sigma: MET siRNA1 (SASI_Hs01_00133002) and siRNA12 (SASI_WI_00000001). siRNA was delivered into CAOV4 ovarian cancer cells by AMAXA electroporation (Kit T, Program T-020, Lonza).

\section{Cell proliferation assay}

CellTiter-Glo luminescent cell viability assay (Promega) was used to evaluate the role of FER in ovarian cancer cell proliferation. In brief, $1.5 \times 10^{3}$ cells per well were seeded in a 96-well plate and grown for the indicated time intervals. CellTiter-Glo reagent was added to each well and mixed for $\sim 15 \mathrm{~min}$ on an orbital shaker to induce cell lysis followed by luminescence reading. Results represent mean \pm SEM from three independent experiments.

\section{Cell migration and invasion assays}

Cell motility was measured using cell culture inserts $(8.0-\mu \mathrm{m}$ pore size) for six-well plates (BD Falcon). Cell invasion was quantitated using BioCoat BD Matrigel invasion chambers $(8.0-\mu \mathrm{m}$ pore size). Cells $\left(2 \times 10^{5}\right)$ were grown in the insert. After $24 \mathrm{~h}$, those cells retained inside the insert were removed, and those that migrated to the other side of the insert were fixed and stained with Karyomax Giemsa stain (Gibco, Invitrogen). 


\section{Wound healing assay}

To measure cell migration, a confluent monolayer of cells was "wounded" by scraping a $200-\mu \mathrm{L}$ pipette tip across the monolayer to produce lesions with a constant length. Any loose cells were removed by washing three times with PBS. Phase images were taken by a Zeiss Axiovert $200 \mathrm{M}$ using AxioVision 4.4 software.

\section{Immunofluorescence}

Cells were fixed for $15 \mathrm{~min}$ in $3.6 \%$ formaldehyde diluted in PBS. After washing with PBS, the cells were incubated in 100\% icecold methanol for $10 \mathrm{~min}$ at $-20^{\circ} \mathrm{C}$. Following fixation, cells were incubated in blocking solution $15 \%$ goat serum, $0.3 \%$ Triton $\mathrm{X}-100$ in PBS) for $1 \mathrm{~h}$ at room temperature and then incubated with primary antibodies diluted in blocking solution overnight at $4^{\circ} \mathrm{C}$. Following washing with PBS, the cells were stained with secondary antibodies diluted in blocking solution for $1 \mathrm{~h}$ at room temperature. The nuclei of the cells were highlighted by DAPI. The cells were mounted in Prolong Antifade (Molecular Probe, Invitrogen)

\section{RNA extraction and quantitative RT-PCR ( $q R T-P C R$ )}

Total RNA was extracted from ovarian cancer cells using the TRIzol reagent (Tel-Test, Inc.) according to the manufacturer's instructions. Two micrograms of RNA was used for cDNA synthesis with iScript (Bio-Rad). RNA expression was measured by real-time qRT-PCR using the SYBR Green method (Applied Biosystems). Each assay was done in triplicate, and the expression of each gene was calculated relative to the expression of $\beta$-actin cDNA.

\section{Immunoblotting, immunoprecipitation, and GST pull-down assay}

Cell extracts were prepared in RIPA lysis buffer $150 \mathrm{mM}$ Tris $\mathrm{HCl}$ at $\mathrm{pH} 8,150 \mathrm{mM} \mathrm{NaCl}, 1 \% \mathrm{NP}-40,0.5 \%$ sodium deoxycholate, $0.1 \%$ SDS) containing $50 \mathrm{mM}$ sodium fluoride, $1 \mathrm{mM}$ sodium orthovanadate, and $1 \times$ Complete protease inhibitor cocktail (Roche). Total protein concentration was determined by the Bradford assay. The primary antibodies used were as follows: $\mathrm{p}$-Tyr (4G10: Millipore; pY20: Sigma,); Myc (9E10), PTP1B (FG6); FER, pErk1/2, Erk1/2, pY1234/1235 MET, pY1349 MET, MET, pY580 SHP2, SHP2, pS473 AKT, pT308 AKT, AKT, pY416 SRC, pY527 SRC, SRC, pY1068 EGFR, EGFR, pY705 STAT3, STAT3, pY627 GAB1, GAB1, $\beta$-catenin, pY421 cortactin, cortactin, pY165 p130CAS, p130CAS, PAK1, PAK2, PAK4, pS144 PAK1, RAC1, pY397 FAK, pY576 FAK, pY861 FAK, and FAK (Cell Signaling Technology); pp38 (Promega); p38 and BRK (Santa Cruz Biotechnology); pY402 FER and pY342 BRK (Millipore); pY142 $\beta$-catenin (Abcam); and $\beta$-tubulin and $\beta$-actin (Sigma). Precleared cell extracts were incubated with the indicated antibody for $4 \mathrm{~h}$ in a cold room with rotation followed by $1 \mathrm{~h}$ of pulldown by $1: 1$ protein $\mathrm{A} / \mathrm{G}$ agarose beads. Immunoprecipitates were washed with lysis buffer three times before electrophoresis. For GST pull-down assays, precleared cell extracts were incubated with GST-RBD (RAC-binding domain on PAK; a gift from Linda Van Aelst's laboratory, Cold Spring Harbor Laboratory) for $4 \mathrm{~h}$ at $4^{\circ} \mathrm{C}$ with rotation. Immunoprecipitates were washed in lysis buffer three times before electrophoresis.

\section{Animal work}

All study protocols involving mice were approved by the Institutional Animal Care and Use Committee of the Cold Spring Har- bor Laboratory and conducted in accordance with National Institutes of Health guidelines for the care and use of animals. In the subcutaneous injection model, $1 \times 10^{6} \mathrm{CAOV} 4$ cells expressing shCon or shFER with a luciferase expression cassette were suspended in $10 \mu \mathrm{L}$ of 1:1 mixture with DMEM and growth factor-reduced Matrigel (BD Biosciences) and subcutaneously injected into SCID-Beige mice (Taconic Laboratory). Subcutaneous tumor growth was monitored periodically by injecting $100 \mu \mathrm{L}$ of $15 \mathrm{mg} / \mathrm{kg}$ D-luciferin (Gold Biotechnology) intraperitoneally and imaging the animal using a Xenogen imager (Xenogen IVIS200 Optical in vivo imaging system). Tumor volume (in cubic millimeters) was measured with calipers before imaging (formula: volume $=$ width $^{2} \times$ length $/ 2$ ). A secondary surgery was performed to remove subcutaneous tumors $5 \mathrm{wk}$ after inoculation. The volume (in cubic millimeters) and weight (in grams) of all subcutaneous tumors were measured. The clearance of subcutaneous tumors was examined $4 \mathrm{~d}$ after surgical resection by imaging. The recurrence of tumors was continually monitored twice a week by luminescence imaging until $10 \mathrm{wk}$ after the first xenograft. Lung, liver, and bone tissues were harvested and submerged for $3 \mathrm{~min}$ in D-luciferin for ex vivo luminescence imaging. All tissues were rinsed in DPBS and fixed in formaldehyde solution (Sigma) for immunohistochemistry analysis.

In the intraperitoneal injection model, $5 \times 10^{6} \mathrm{CAOV} 4$ cells expressing shCon or shFER were suspended in $500 \mu \mathrm{L}$ of sterilized PBS and intraperitoneally injected into SCID-Beige mice (Taconic Laboratory). Four weeks later, necropsy procedures were performed to assess tumor spreading in the peritoneal cavity of the mice.

\section{Histology}

Paraffin-embedded tissues were sectioned and stained with $\mathrm{H} \& \mathrm{E}$ or specific immunohistochemical stains. The following primary antibodies were used for immunohistochemical staining: HGF (AF-294), pY1349 MET (AF3950), and pY1234,1235 MET (AF2480) (R\&D Systems); and FER (Haigh et al. 1996). Slides were digitally scanned using the Aperio ScanScope software.

\section{Statistics}

All statistics were performed using a standard Student's $t$-test.

\section{Acknowledgments}

We thank Dr. Robert Lucito (Hofstra University) for helpful comments in the preparation of the manuscript, Dr. Morag Park (McGill University) and Dr. Linda Van Aelst (Cold Spring Harbor Laboratory [CSHL]) for providing plasmid constructs, Raisa Puzis (Animal and Tissue Imaging Shared Resource, CSHL Cancer Center) for assistance with immunohistochemistry staining, Pamela Moody (Flow Cytometry Shared Resource, CSHL Cancer Center) for helping with flow cytometry analysis, and Stephan Hearn (Microscopy Shared Resource, CSHL Cancer Center) for helping with image capture. We also thank Dr. Anne-Marie Mes-Masson (University of Montreal), Dr. Hongwu Zheng, Dr. Senthil K. Muthuswamy, and Dr. Michael Feigin for insightful discussions. This work was supported by National Institutes of Health grants CA53840 and GM55989 to N.K.T., Canadian Institutes of Health Research grant 219806 to P.A.G., and Cold Spring Harbor Laboratory Cancer Center Support Grant CA45508. N.K.T. is also grateful for support from the following foundations: the Gladowsky Breast Cancer Foundation, the Don Monti Memorial Research Foundation, the Irving Hansen Foundation, West Islip Breast 
Cancer Coalition for Long Island, Glen Cove CARES, Find a Cure Today (FACT), Constance Silveri, the Robertson Research Fund, and the Masthead Cove Yacht Club Carol Marcincuk Fund. G. F., P.A.G., and N.K.T. designed the study. G.F. contributed to all aspects of the experimental work. S.Z. and Y.G. contributed to the animal work. All of the authors contributed to the analysis of the data. G.F. and N.K.T. wrote the paper.

\section{References}

Ahn J, Truesdell P, Meens J, Kadish C, Yang X, Boag AH, Craig AW. 2013. Fer protein-tyrosine kinase promotes lung adenocarcinoma cell invasion and tumor metastasis. Mol Cancer Res 11: 952-963.

Albeck JG, Brugge JS. 2011. Uncovering a tumor suppressor for triple-negative breast cancers. Cell 144: 638-640.

Arend RC, Londono-Joshi AI, Straughn JM Jr, Buchsbaum DJ. 2013. The Wnt/ $\beta$-catenin pathway in ovarian cancer: a review. Gynecol Oncol 131: 772-779.

Ayhan A, Ertunc D, Tok EC, Ayhan A. 2005. Expression of the cMet in advanced epithelial ovarian cancer and its prognostic significance. Int J Gynecol Cancer 15: 618-623.

Barbolina MV, Burkhalter RJ, Stack MS. 2011. Diverse mechanisms for activation of Wnt signalling in the ovarian tumour microenvironment. Biochem J 437: 1-12.

Birchmeier C, Birchmeier W, Gherardi E, Vande Woude GF. 2003. Met, metastasis, motility and more. Nat Rev Mol Cell Biol 4: 915-925.

Boccaccio C, Comoglio PM. 2006. Invasive growth: a MET-driven genetic programme for cancer and stem cells. Nat Rev Cancer 6: 637-645.

Cantelmo AR, Cammarota R, Noonan DM, Focaccetti C, Comoglio PM, Prat M, Albini A. 2010. Cell delivery of Met docking site peptides inhibit angiogenesis and vascular tumor growth. Oncogene 29: 5286-5298.

Cepero V, Sierra JR, Corso S, Ghiso E, Casorzo L, Perera T, Comoglio PM, Giordano S. 2010. MET and KRAS gene amplification mediates acquired resistance to MET tyrosine kinase inhibitors. Cancer Res 70: 7580-7590.

Cho KW, Park JH, Park CW, Lee D, Lee E, Kim DJ, Kim KJ, Yoon SH, Park Y, Kim E, et al. 2013. Identification of a pivotal endocytosis motif in c-Met and selective modulation of HGF-dependent aggressiveness of cancer using the 16-mer endocytic peptide. Oncogene 32: 1018-1029.

Christensen JG, Schreck R, Burrows J, Kuruganti P, Chan E, Le P, Chen J, Wang X, Ruslim L, Blake R, et al. 2003. A selective small molecule inhibitor of c-Met kinase inhibits c-Met-dependent phenotypes in vitro and exhibits cytoreductive antitumor activity in vivo. Cancer Res 63: 7345-7355.

Cole LA, Zirngibl R, Craig AW, Jia Z, Greer P. 1999. Mutation of a highly conserved aspartate residue in subdomain IX abolishes Fer protein-tyrosine kinase activity. Protein Eng 12: 155-162.

Comoglio PM, Giordano S, Trusolino L. 2008. Drug development of MET inhibitors: targeting oncogene addiction and expedience. Nat Rev Drug Discov 7: 504-516.

Craig AW. 2012. FES/FER kinase signaling in hematopoietic cells and leukemias. Front Biosci (Landmark Ed) 17: 861-875.

Craig AW, Zirngibl R, Williams K, Cole LA, Greer PA. 2001. Mice devoid of fer protein-tyrosine kinase activity are viable and fertile but display reduced cortactin phosphorylation. Mol Cell Biol 21: 603-613.

Domcke S, Sinha R, Levine DA, Sander C, Schultz N. 2013. Evaluating cell lines as tumour models by comparison of genomic profiles. Nat Commun 4: 2126.
Fan G, Lin G, Lucito R, Tonks NK. 2013. Protein-tyrosine phosphatase $1 \mathrm{~B}$ antagonized signaling by insulin-like growth factor- 1 receptor and kinase BRK/PTK6 in ovarian cancer cells. J Biol Chem 288: 24923-24934.

Fan G, Aleem S, Yang M, Miller WT, Tonks NK. 2015. Protein-tyrosine phosphatase and kinase specificity in regulation of SRC and breast tumor kinase. J Biol Chem 290: 15934-15947.

Fei F, Kweon SM, Haataja L, De Sepulveda P, Groffen J, Heisterkamp N. 2010. The Fer tyrosine kinase regulates interactions of Rho GDP-dissociation inhibitor a with the small GTPase Rac. BMC Biochem 11: 48.

Filippakopoulos P, Kofler M, Hantschel O, Gish GD, Grebien F, Salah E, Neudecker P, Kay LE, Turk BE, Superti-Furga G, et al. 2008. Structural coupling of SH2-kinase domains links Fes and Abl substrate recognition and kinase activation. Cell 134: 793-803.

Gherardi E, Birchmeier W, Birchmeier C, Vande Woude G. 2012. Targeting MET in cancer: rationale and progress. Nat Rev Cancer 12: 89-103.

Gordon MS, Sweeney CS, Mendelson DS, Eckhardt SG, Anderson A, Beaupre DM, Branstetter D, Burgess TL, Coxon A, Deng H, et al. 2010. Safety, pharmacokinetics, and pharmacodynamics of AMG 102, a fully human hepatocyte growth factor-neutralizing monoclonal antibody, in a first-in-human study of patients with advanced solid tumors. Clin Cancer Research 16: 699-710.

Greer P. 2002. Closing in on the biological functions of Fps/Fes and Fer. Nat Rev Mol Cell Biol 3: 278-289.

Guo C, Stark GR. 2011. FER tyrosine kinase (FER) overexpression mediates resistance to quinacrine through EGF-dependent activation of NF-кB. Proc Natl Acad Sci 108: 7968-7973.

Haigh J, McVeigh J, Greer P. 1996. The fps/fes tyrosine kinase is expressed in myeloid, vascular endothelial, epithelial, and neuronal cells and is localized in the trans-golgi network. Cell Growth Differ 7: 931-944.

Hellwig S, Miduturu CV, Kanda S, Zhang J, Filippakopoulos P, Salah E, Deng X, Choi HG, Zhou W, Hur W, et al. 2012. Small-molecule inhibitors of the c-Fes protein-tyrosine kinase. Chem Biol 19: 529-540.

Huntsman D, Resau JH, Klineberg E, Auersperg N. 1999. Comparison of c-met expression in ovarian epithelial tumors and normal epithelia of the female reproductive tract by quantitative laser scan microscopy. Am J Pathol 155: 343-348.

Itoh T, Hasegawa J, Tsujita K, Kanaho Y, Takenawa T. 2009. The tyrosine kinase Fer is a downstream target of the PLD-PA pathway that regulates cell migration. Sci Signal 2: ra52.

Ivanova IA, Vermeulen JF, Ercan C, Houthuijzen JM, Saig FA, Vlug EJ, van der Wall E, van Diest PJ, Vooijs M, Derksen PW. 2013. FER kinase promotes breast cancer metastasis by regulating a6- and $\beta 1$-integrin-dependent cell adhesion and anoikis resistance. Oncogene 32: 5582-5592.

Kim L, Wong TW. 1995. The cytoplasmic tyrosine kinase FER is associated with the catenin-like substrate pp120 and is activated by growth factors. Mol Cell Biol 15: 4553-4561.

Kogata N, Masuda M, Kamioka Y, Yamagishi A, Endo A, Okada M, Mochizuki N. 2003. Identification of Fer tyrosine kinase localized on microtubules as a platelet endothelial cell adhesion molecule-1 phosphorylating kinase in vascular endothelial cells. Mol Biol Cell 14: 3553-3564.

Koon EC, Ma PC, Salgia R, Welch WR, Christensen JG, Berkowitz RS, Mok SC. 2008. Effect of a c-Met-specific, ATP-competitive small-molecule inhibitor SU1 1274 on human ovarian carcinoma cell growth, motility, and invasion. Int I Gynecol Cancer 18: 976-984. 
Lai AZ, Cory S, Zhao H, Gigoux M, Monast A, Guiot MC, Huang S, Tofigh A, Thompson C, Naujokas M, et al. 2014. Dynamic reprogramming of signaling upon met inhibition reveals a mechanism of drug resistance in gastric cancer. Sci Signal 7: ra38.

Li H, Ren Z, Kang X, Zhang L, Li X, Wang Y, Xue T, Shen Y, Liu Y. 2009. Identification of tyrosine-phosphorylated proteins associated with metastasis and functional analysis of FER in human hepatocellular carcinoma cells. BMC Cancer 9: 366.

Liu X, Newton RC, Scherle PA. 2010. Developing c-MET pathway inhibitors for cancer therapy: progress and challenges. Trends Mol Med 16: 37-45.

Longuespee R, Boyon C, Desmons A, Vinatier D, Leblanc E, Farre I, Wisztorski M, Ly K, D'Anjou F, Day R, et al. 2012. Ovarian cancer molecular pathology. Cancer Metastasis Rev 31: 713-732.

Molli PR, Li DQ, Murray BW, Rayala SK, Kumar R. 2009. PAK signaling in oncogenesis. Oncogene 28: 2545-2555.

Nguyen L, Holgado-Madruga M, Maroun C, Fixman ED, Kamikura D, Fournier T, Charest A, Tremblay ML, Wong AJ, Park M. 1997. Association of the multisubstrate docking protein Gab1 with the hepatocyte growth factor receptor requires a functional Grb2 binding site involving tyrosine 1356. I Biol Chem 272: 20811-20819.

Petti C, Picco G, Martelli ML, Trisolini E, Bucci E, Perera T, Isella C, Medico E. 2015. Truncated RAF kinases drive resistance to MET inhibition in MET-addicted cancer cells. Oncotarget 6: 221-233.

Piedra J, Miravet S, Castano J, Palmer HG, Heisterkamp N, Garcia de Herreros A, Dunach M. 2003. p120 Catenin-associated Fer and Fyn tyrosine kinases regulate $\beta$-catenin Tyr-142 phosphorylation and $\beta$-catenin- $\alpha$-catenin interaction. Mol Cell Biol 23: 2287-2297.

Priel-Halachmi S, Ben-Dor I, Shpungin S, Tennenbaum T, Molavani H, Bachrach M, Salzberg S, Nir U. 2000. FER kinase activation of Stat3 is determined by the $\mathrm{N}$-terminal sequence. J Biol Chem 275: 28902-28910.

Ren H, Tan ZP, Zhu X, Crosby K, Haack H, Ren JM, Beausoleil S, Moritz A, Innocenti G, Rush J, et al. 2012. Identification of anaplastic lymphoma kinase as a potential therapeutic target in ovarian cancer. Cancer Res 72: 3312-3323.

Rikova K, Guo A, Zeng Q, Possemato A, Yu J, Haack H, Nardone J, Lee K, Reeves C, Li Y, et al. 2007. Global survey of phosphotyrosine signaling identifies oncogenic kinases in lung cancer. Cell 131: 1190-1203.

Sangrar W, Gao Y, Scott M, Truesdell P, Greer PA. 2007. Fer-mediated cortactin phosphorylation is associated with efficient fibroblast migration and is dependent on reactive oxygen species generation during integrin-mediated cell adhesion. Mol Cell Biol 27: 6140-6152.

Sangrar W, Shi C, Mullins G, LeBrun D, Ingalls B, Greer PA. 2015. Amplified Ras-MAPK signal states correlate with accelerated EGFR internalization, cytostasis and delayed HER2 tumor onset in Fer-deficient model systems. Oncogene 34: 4109-4117.
Sawada K, Radjabi AR, Shinomiya N, Kistner E, Kenny H, Becker AR, Turkyilmaz MA, Salgia R, Yamada SD, Vande Woude GF, et al. 2007. c-Met overexpression is a prognostic factor in ovarian cancer and an effective target for inhibition of peritoneal dissemination and invasion. Cancer Res 67: 1670-1679.

Siegel RL, Miller KD, Jemal A. 2015. Cancer statistics, 2015. CA Cancer J Clin 65: 5-29.

Slack-Davis JK, Atkins KA, Harrer C, Hershey ED, Conaway M. 2009. Vascular cell adhesion molecule-1 is a regulator of ovarian cancer peritoneal metastasis. Cancer Res 69: 1469-1476.

Trusolino L, Bertotti A, Comoglio PM. 2010. MET signalling: principles and functions in development, organ regeneration and cancer. Nat Rev Mol Cell Biol 11: 834-848.

Tsao SW, Mok SC, Fey EG, Fletcher JA, Wan TS, Chew EC, Muto MG, Knapp RC, Berkowitz RS. 1995. Characterization of human ovarian surface epithelial cells immortalized by human papilloma viral oncogenes (HPV-E6E7 ORFs). Exp Cell Res 218: 499-507.

Tsujita K, Suetsugu S, Sasaki N, Furutani M, Oikawa T, Takenawa T. 2006. Coordination between the actin cytoskeleton and membrane deformation by a novel membrane tubulation domain of $\mathrm{PCH}$ proteins is involved in endocytosis. J Cell Biol 172: 269-279.

Weidner KM, Di Cesare S, Sachs M, Brinkmann V, Behrens J, Birchmeier W. 1996. Interaction between Gab1 and the cMet receptor tyrosine kinase is responsible for epithelial morphogenesis. Nature 384: 173-176.

Wong AS, Pelech SL, Woo MM, Yim G, Rosen B, Ehlen T, Leung PC, Auersperg N. 2001. Coexpression of hepatocyte growth factor-Met: an early step in ovarian carcinogenesis? Oncogene 20: $1318-1328$.

Wu R, Hendrix-Lucas N, Kuick R, Zhai Y, Schwartz DR, Akyol A, Hanash S, Misek DE, Katabuchi H, Williams BO, et al. 2007. Mouse model of human ovarian endometrioid adenocarcinoma based on somatic defects in the Wnt $/ \beta$-catenin and PI3K/ Pten signaling pathways. Cancer Cell 11: 321-333.

Xu G, Craig AW, Greer P, Miller M, Anastasiadis PZ, Lilien J, Balsamo J. 2004. Continuous association of cadherin with $\beta$-catenin requires the non-receptor tyrosine-kinase Fer. J Cell Sci 117: 3207-3219.

Yoneyama T, Angata K, Bao X, Courtneidge S, Chanda SK, Fukuda M. 2012. Fer kinase regulates cell migration through a-dystroglycan glycosylation. Mol Biol Cell 23: 771-780.

Zhang SQ, Tsiaras WG, Araki T, Wen G, Minichiello L, Klein R, Neel BG. 2002. Receptor-specific regulation of phosphatidylinositol 3'-kinase activation by the protein tyrosine phosphatase Shp2. Mol Cell Biol 22: 4062-4072.

Zoubeidi A, Rocha J, Zouanat FZ, Hamel L, Scarlata E, Aprikian AG, Chevalier S. 2009. The Fer tyrosine kinase cooperates with interleukin- 6 to activate signal transducer and activator of transcription 3 and promote human prostate cancer cell growth. Mol Cancer Res 7: 142-155. 


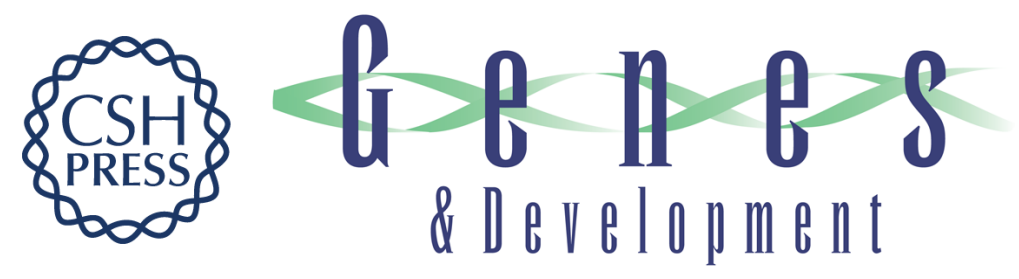

\section{HGF-independent regulation of MET and GAB1 by nonreceptor tyrosine kinase FER potentiates metastasis in ovarian cancer}

Gaofeng Fan, Siwei Zhang, Yan Gao, et al.

Genes Dev. 2016, 30:

Access the most recent version at doi:10.1101/gad.284166.116

Supplemental http://genesdev.cshlp.org/content/suppl/2016/07/11/30.13.1542.DC1
Material

References This article cites 58 articles, 25 of which can be accessed free at:

http://genesdev.cshlp.org/content/30/13/1542.full.html\#ref-list-1

Creative This article is distributed exclusively by Cold Spring Harbor Laboratory Press for the first

Commons six months after the full-issue publication date (see

License http://genesdev.cshlp.org/site/misc/terms.xhtml). After six months, it is available under a Creative Commons License (Attribution-NonCommercial 4.0 International), as described at http://creativecommons.org/licenses/by-nc/4.0/.

Email Alerting Receive free email alerts when new articles cite this article - sign up in the box at the top Service right corner of the article or click here.

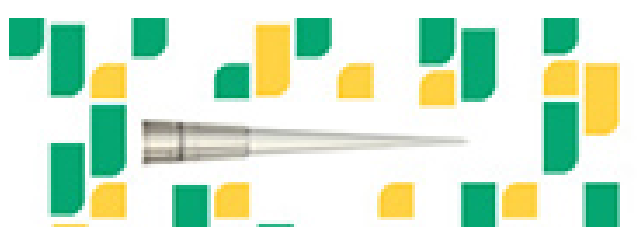

Focused on your science. 